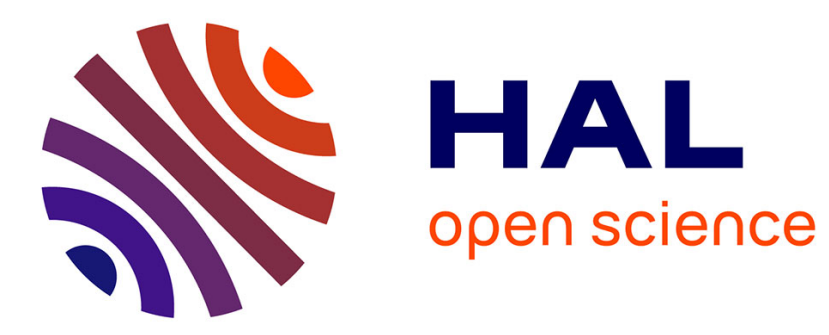

\title{
Earth-Abundant d-Block Metal Nanocatalysis for Coupling Reactions in Polyols
}

\author{
Marc Camats, Daniel Pla, Montserrat Gomez
}

\section{To cite this version:}

Marc Camats, Daniel Pla, Montserrat Gomez. Earth-Abundant d-Block Metal Nanocatalysis for Coupling Reactions in Polyols. Recent advances in nanoparticle catalysis, 2020. hal-03011363

\section{HAL Id: hal-03011363 https://hal.science/hal-03011363}

Submitted on 18 Nov 2020

HAL is a multi-disciplinary open access archive for the deposit and dissemination of scientific research documents, whether they are published or not. The documents may come from teaching and research institutions in France or abroad, or from public or private research centers.
L'archive ouverte pluridisciplinaire HAL, est destinée au dépôt et à la diffusion de documents scientifiques de niveau recherche, publiés ou non, émanant des établissements d'enseignement et de recherche français ou étrangers, des laboratoires publics ou privés. 


\title{
Chapter 8 \\ Earth-Abundant D-Block Metal Nanocatalysis for Coupling Reactions in Polyols
}

\author{
Marc Camats, Daniel Pla, and Montserrat Gómez
}

Abstract Green Chemistry concepts have directed chemists to conceive and develop sustainable procedures, from the starting materials choice through reaction and analysis conditions, including suitable engineering aspects, to the impact of products, comprising recycling, and waste management. Industrial processes in Fine and Pharmaceutical Chemistry sector have high E factors compared to oil and bulk chemicals industry. Thus, the development of catalytic methods leading to high added value products is crucial, as well as waste minimization through selective transformations. Catalysts from 3d metals, compared to "heavy" metals, are greener, although a combination of different approaches is needed for efficient and viable processes. In contrast to $4 \mathrm{~d}$ and $5 \mathrm{~d}$ metals, catalysis with earth-abundant metals is less developed, even less concerning nanocatalysts. Metal nanoparticles, due to their unique electronic and structural properties, induce original reactivities allowing a plethora of transformations. Besides, solvents, present in most steps, represent a major economic and environmental concern. In addition, they can have a dramatic influence on the stabilization of MNP and hence, a huge impact on catalytic activity and recycling. This chapter gives a perspective on $3 \mathrm{~d}$ metal-based nanocatalysts in polyols applied in couplings, reactions present in many methodologies to produce fine chemicals in a sustainable fashion.

Keywords $3 \mathrm{~d}$ metals $\cdot$ Metal nanoparticles $\cdot$ Catalysis $\cdot$ Couplings $\cdot$ Polyols

Dedicated to Prof. Guillermo Muller for his thorough contributions in Organometallic Chemistry and Homogeneous Catalysis.

M. Camats · D. Pla · M. Gómez (凶)

Laboratoire Hétérochimie Fondamentale et Appliquée (UMR 5069), Université de Toulouse, CNRS, 118 Route de Narbonne, 31062 Toulouse Cedex 9, France

e-mail: gomez@chimie.ups-tlse.fr

D. $\mathrm{Pla}$

e-mail: pla@1hfa.fr 


\subsection{Introduction}

In the 1990s, a ground-breaking movement concerning the Earth preservation for future generations has appeared. In Chemistry, these actions led to the Green Chemistry concept ("Green Chemistry" by Paul et al. [57], Warner et al. [128] articulated through the 12 Green Chemistry Principles [6]; shortly after, the Sandestin declaration established the bases of the Green Engineering Principles [8]. Without any doubt, catalysis is one of the most important pillars of Green approaches [7]. Analyzing the evolution of metal-based catalysis, involving homogeneous and heterogeneous systems, it is evident to conclude that definitely the twentieth century has been the century of "heavy" metal-based catalysts, i.e., catalytic processes concerning $4 \mathrm{~d}$ and $5 \mathrm{~d}$ metals (such as $\mathrm{Mo}, \mathrm{Ru}, \mathrm{Rh}, \mathrm{Ir}, \mathrm{Pd}, \mathrm{Pt}, \mathrm{Au} . .$. ), as internationally acknowledged by the Nobel Prizes in 2005 (Y. Chauvin, R. H. Grubbs and R. R. Schrock) and 2010 (R. F. Heck, E.-i. Negishi and A. Suzuki) for the development of metathesis processes (mainly Mo- and Ru-based catalysts) and Pd-catalyzed couplings in organic synthesis, respectively (www.nobelprize.org/prizes/chemistry/2005/summary; www.nobelprize.org/prizes/chemistry/2010/summary). Nevertheless, nature has exploited earth abundant $3 \mathrm{~d}$ metals $(\mathrm{Fe}, \mathrm{Ni}, \mathrm{Cu}, \mathrm{Zn} \ldots)$, leading to metalloenzymes which exhibit a prominent specificity [15]. In coherence to a sustainable development, researches on the design of manufactured catalysts with first-row transition metals have exponentially grown since the 2000s (see the contributions collected in the special issue "First row metals and catalysis" of Chemical Reviews, 2019) [2, 4, 46, 48, 64, 78, 100, 123, 129] (Fig. 8.1).

On the other hand, solvents represent one of the major concerns for chemical transformations (employed in synthesis, extractions, purifications, analyses...), in particular volatile organic compounds which are generally toxic showing different levels of harmfulness and danger, submitted to severe regulations. Alternative solvents (water, ionic liquids and deep eutectic solvents, alcohols, supercritical fluids,

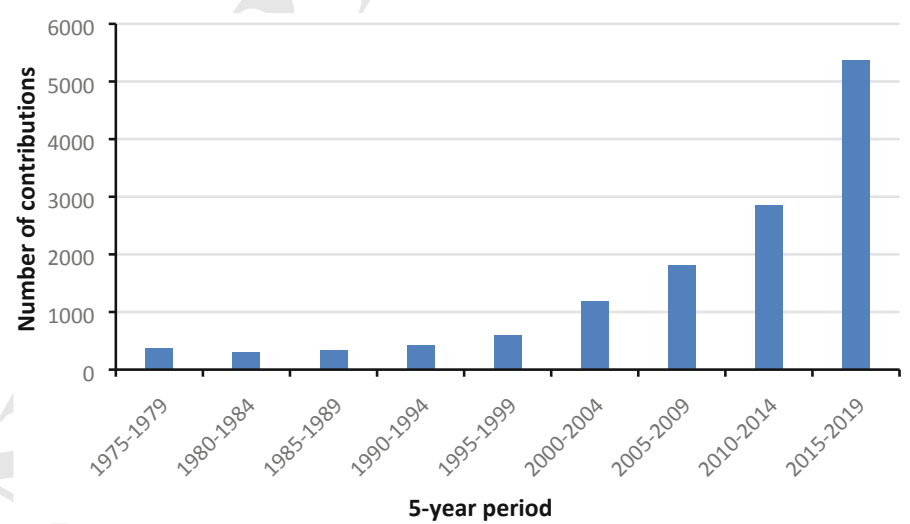

Fig. 8.1 Published contributions per 5-year period for first-row transition metals used in catalysis (data collected from SciFinder Database since 1975 up to July 2019) 
renewable solvents, combination of different solvents...) and solvent-free chemistry are useful and efficient approaches for many applications, needing investment and effort to adapt the current processes to the new reaction conditions [68]. In the frame of this chapter, we are interested in polyols, largely used in the industrial sector (highlighting the production of polymers such as polyurethanes, polyvinyl alcohol ...), because they present lower environmental impact than low-weight and volatile organic compounds, and they are particularly attractive for the synthesis and stabilization of nano-sized metal clusters.

Focusing on this type of nanomaterials, well-defined metal-based nanoparticles (objects showing dimensions in the range 1-100 $\mathrm{nm}$ ) have known a huge expansion since the 1980s due to their distinctive properties, both physical and chemical, in comparison to molecular and bulk materials. Actually, this is a consequence of their electronic and structural features, making possible a vast number of applications [110, 121, 133], in particular in catalysis [1, 54, 88, 110, 111]. Even though metal nanoparticles (MNPs) have been largely applied in classical heterogeneous catalysis, with crucial participation in industrial processes mainly those related to oil area [136], nanocatalysis, which concerns MNPs dispersed in a solvent have been only developed since the end of the last century. This exponential growth has benefited of the recent advances in characterization techniques (including operando approaches) which has permitted the design of catalysts at nanometric scale by means of controlling morphology and surface state of nanoobjects [5, 9, 62, 89]. Noticeably, reproducible synthetic methodologies are crucial for their further applications $[106,122]$. The chemical strategies (commonly named bottom-up syntheses) often include solvents, from conventional organic compounds to alternative ones (showing a lower environmental impact), such as water [20, 109], ionic liquids [104], $\mathrm{scCO}_{2}$, $[30,99,134]$, polyols $[22,38,41]$. It is important to mention that solvents may be involved in different aspects, for example, as reducing agents, stabilizers, or medium for trapping nanocatalysts preserving their morphology during the catalytic transformation and thus facilitating their recycling. This is the case when polyols are present. In 1989, the polyol methodology was for the first time reported by Fiévet and coworkers where metal salts were reduced in ethylene glycol, obtaining welldefined MNPs [42, 43]. In this method, the polyol acts as solvent, reducing agent, and stabilizer when higher polyols are involved (e.g., polyphenols or polysaccharides), which prevents the agglomeration of MNPs in solution [34, 41].

These privileged physicochemical properties favor the preparation of tailor-made first-row transition metal nanocatalysts and derived nanocomposites in a controlled manner. Rational catalyst design is essential for the preparation of well-defined clusters and nanoparticles with optimal properties in terms of redox control, cooperative effects, and increased surface areas, all of them are key factors for catalysis. Beyond the dual catalytic behavior related to both surface and reservoir of molecular species, nanocatalysis brings novel reaction manifolds due to the unique structural properties of MNPs, particularly their differential electronic structure as compared to bulk metals (e.g., facilitating single electron transfer processes via the Fermi level for electrons [40]). 
In the present contribution, we focus on the recent advances in $3 \mathrm{~d}$ metal nanocatalysts (for a recent review, see: [127]), involving polyols acting as stabilizer and/or reaction medium for coupling reactions, Carbon-Carbon and Carbon-Heteroatom bond formation processes, including multicomponent syntheses.

\subsection{Carbon-Carbon Bond Formation}

$\mathrm{C}-\mathrm{C}$ cross-coupling reactions have been largely dominated by palladium-based catalyzed processes due to their efficiency and versatility. In particular, the ability of this metal to stabilize different kinds of species (complexes, nanoparticles, extended surfaces) and its relatively high robustness under many different reaction conditions has permitted the elucidation of the corresponding mechanisms [17, 119, 124]. From a sustainable chemistry point of view, the use of first-row transition metals is obviously preferred and a huge research has been developed in the last years (for instance, see the contributions published in the Accounts of Chemical Research special issue "Earth Abundant Metals in Homogeneous Catalysis," [26]).

\subsubsection{Lewis Acid-Catalyzed Coupling Reactions}

Heterocyclic motifs are present in a large variety of naturally occurring products along with industrial compounds [35, 58, 65, 101]. Multicomponent reactions represent an environmentally friendly approach to prepare polyfunctional compounds, in particular heterocycle derivatives, via one-pot processes involving three or more reactants, with high atom economy and easy implementation $[18,130,138]$. These transformations are often promoted by Lewis acids, which favor the kinetics directing the reaction pathway and in consequence improving the selectivity [49]. In this frame, Khurana and coworkers reported nickel nanoparticles (NiNPs) stabilized by polyethylene glycol (PEG-4000) and prepared by polyol-based methodology using ethylene glycol in the presence of $\mathrm{NaBH}_{4}$, which was applied in the synthesis of spiropyrans [72], interesting materials particularly due to their unique molecular switch triggering structural isomerization under the effect of different external stimuli (light, mechanical stress, temperature...) [74, 82, 131]. They were synthesized by a multicomponent reaction, constituted of a tandem Knoevenagel-cyclo-condensation involving ninhydrin (or related cyclic dicarbonyl compounds), malonitrile, and dimedone (or related 1,3-dicarbonyl derivatives) (Scheme 8.1). The role of the nanocatalyst (mean size: ca. $7 \mathrm{~nm}$ determined by TEM) was evidenced by different control tests; in the absence of nickel, the reaction was much slower (some hours vs. some minutes) and the use of Ni powder (particle size $<150 \mu \mathrm{m}$ ) led to moderate yields after $8 \mathrm{~h}$ of reaction. Ethylene glycol was a convenient solvent permitting a straightforward biphasic extraction of products by a biphasic system (using ethyl acetate as immiscible soluble with ethylene glycol), preserving the catalyst dispersed in the 
<smiles>O=C1CCC(=O)C1</smiles><smiles>N#CC[N+]1=C[Te]C(=O)CCC1</smiles>

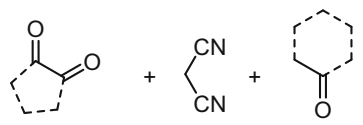

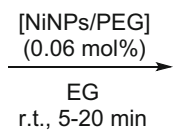<smiles>N#CC1=C(N)OC2=C(C(=O)CC2)C1Br</smiles>

or<smiles>N#CC1=C(N)OC2=C(C(=O)CCC2)C1Br</smiles>

Isolated Yield: 86-96\%<smiles>N#CC1=C(N)OC2=C(CCCC2)C12CCCCO2</smiles>

Scheme 8.1 Synthesis of spiropyrans by a multicomponent reaction catalyzed by NiNPs and stabilized by PEG in ethylene glycol [72]

diol. NiNPs were efficiently reused up to 3 times. Authors postulated that nickel activates carbonyl and nitrile groups.

The same authors previously reported Knoevenagel condensations of barbituric or Meldrum acid and aromatic aldehydes in EG, catalyzed by NiNPs and stabilized by PVP (polyvinylpyrrolidone) [70] and PEG [71], respectively (Scheme 8.2).

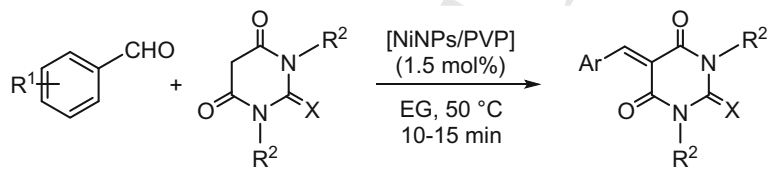

$\mathrm{X}=\mathrm{O}, \mathrm{S}$

Isolated Yield: $82-97 \%$

$\mathrm{R}_{1}=\mathrm{H}, \mathrm{F}, \mathrm{Cl}, \mathrm{Br}, \mathrm{CH}=\mathrm{CH}, \mathrm{CH}_{3}, \mathrm{OH} \ldots$

$\mathrm{R}_{2}=\mathrm{H}, \mathrm{CH}_{3}, \mathrm{Ph}$

$\left(\mathrm{R}_{1}\right.$ in different positions; also polysubstituted aromatic groups)
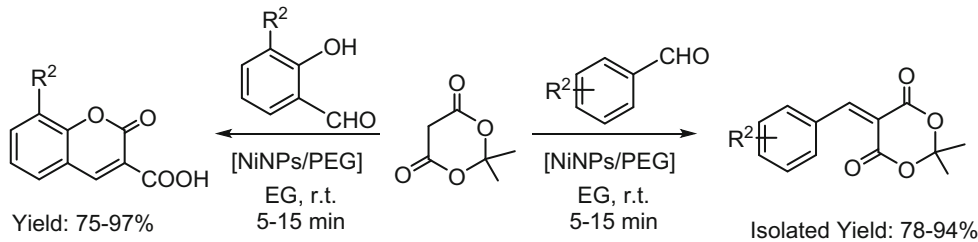

Isolated Yield: 78-94\%

$\mathrm{R}^{1}=\mathrm{H}, \mathrm{Cl}, \mathrm{CH}=\mathrm{CH}, \mathrm{CH}_{3}, \mathrm{OCH}_{3}, \mathrm{OH} \ldots$

$\mathrm{R}^{2}=\mathrm{H}, \mathrm{CH}_{3}, \mathrm{Ph}$

$\left(\mathrm{R}^{1}\right.$ and $\mathrm{R}^{2}$ in different positions; also polysubstituted aromatic groups)

Scheme 8.2 NiNPs stabilized by polymers catalyzed Knoevenagel condensations in ethylene glycol [70, 71] 
Maleki and coworkers synthesized $\mathrm{Fe}_{3} \mathrm{O}_{4}$ nanoparticles stabilized by the biopolymer chitosan coming from chitin (polymer of $\mathrm{N}$-acetylglucosamine) to be applied in three-component reactions yielding benzodiazepines [85] and benzimidazoloquinazolinones [83] (Scheme 8.3), which present biological and pharmacological activities $[24,56]$. For both types of reactions, the catalyst was recycled up to four times preserving its catalytic performance, being ethanol the most appropriate solvent for these catalytic reactions. Authors proposed a similar pathway for both transformations.

In Fig. 8.2, the postulated mechanism for the synthesis of benzimidazolo[2,3$b$ ]quinazolinones is illustrated. The reaction most likely starts by a Knoevenagel<smiles>Nc1ccccc1N</smiles><smiles>CC1(C)CC(=O)CC(=O)C1</smiles><smiles>O=C[Te]</smiles><smiles>CCO[R16](=O)OCC(=O)OCC</smiles><smiles>C=C1CC2=C(C([Al])Nc3ccccc3N2)C(C)(C)C1</smiles>

Isolated Yield: 85-94\%<smiles>[X]c1nc2ccccc2[nH]1</smiles><smiles>[R]c1ccccc1C=O</smiles>

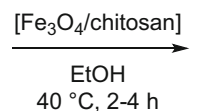<smiles>[X]C1=NC2=C(C(=O)CC(C)(C)C2)C(c2cccc([R])c2)N1c1ccccc1[R]</smiles>

Isolated Yield: 82-95\%

Scheme 8.3 Three-component reactions catalyzed by $\mathrm{Fe}_{3} \mathrm{O}_{4}$ nanoparticles stabilized by chitosan $[83,85]$

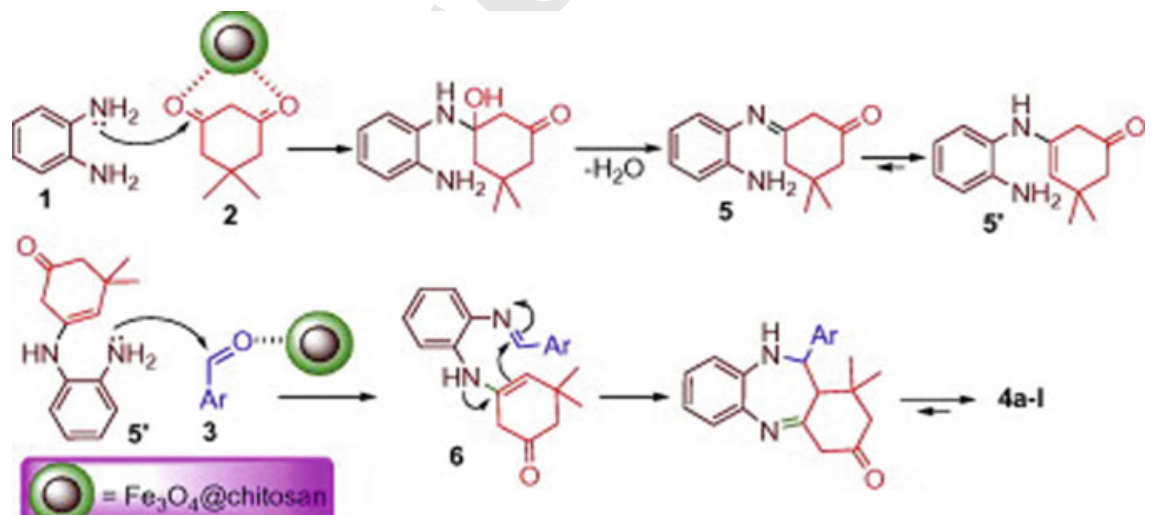

Fig. 8.2 Proposed mechanism for Fe-based catalyzed synthesis of benzimidazolo[2,3$b$ ]quinazolinones. Reprinted from [83] with permission from Elsevier 2015, license no. 4639401066332 
condensation between the aromatic aldehyde and dimedone; the resulting $\alpha, \beta$ unsaturated ketone reacts with the 2 -aminobenzimidazole or its corresponding thioderivative via a Michael addition, giving an acyclic compound which undergoes a further intramolecular cyclization. Similar catalysts were also applied for the synthesis of 2-amino-4H-chromenes [107] and highly substituted pyridines [84].

Although the Lewis acid properties of $\mathrm{Fe}_{3} \mathrm{O}_{4}$ have proven to be useful for the synthesis of heterocycles, these properties seem to be enhanced in the presence of $\mathrm{Cu}$ (II) (Scheme 8.4) [86]. This catalytic system was reused 6 times with slight yield loss (first run: 98\%; sixth run: 91\%).

An interesting variant of this reactivity was reported by Kassanee, showing that chromenylphosphonates could also be prepared in a similar manner in water with high yields and short reaction times (20-30 min), using functionalized magnetite with modified sulfo-chitosan (Scheme 8.5) [92].

Authors propose a mechanism catalyzed by hydrogen-heteroatom (nitrogen or oxygen) interactions, where water is not an innocent solvent (Fig. 8.3). Similar behavior has been observed with magnetite functionalized with sulfo-PEG, $\mathrm{Fe}_{3} \mathrm{O}_{4} @ \mathrm{PEG}-\mathrm{SO}_{3} \mathrm{H}[87]$.

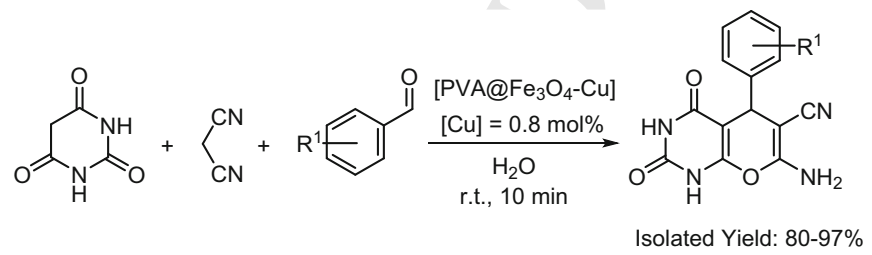

$\mathrm{R}^{1}=\mathrm{H}, \mathrm{Cl}, 2-\mathrm{NO}_{2}, 3-\mathrm{NO}_{2}, 4-\mathrm{OH}, 4-\mathrm{OMe}, 3-\mathrm{OH}, 2-\mathrm{Br}, 4-\mathrm{F}, 4-\mathrm{Br}, 2-\mathrm{OH}, 4-\mathrm{NEt}_{2}$,

Scheme 8.4 Synthesis of pyrano[2,3-d]pyrimidines catalyzed by $\mathrm{Fe}_{3} \mathrm{O}_{4}$ modified with polyvinyl alcohol (PVA) and doped with Cu(II) salts [86]

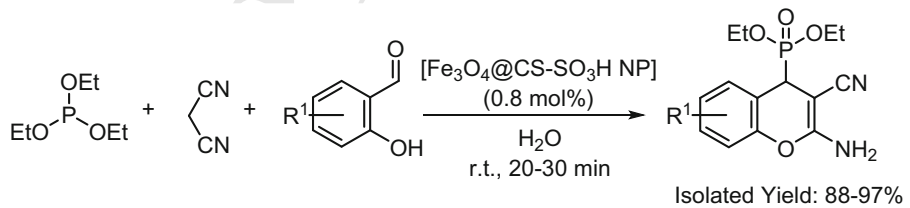

$\mathrm{R}^{1}=\mathrm{H}, 2-\mathrm{Br}, 2,4-\mathrm{Br}, 2-\mathrm{OMe}, 2-\mathrm{Cl}, 2-\mathrm{Me}, 4-\mathrm{OMe}, 3,5-\mathrm{Cl}$

Scheme 8.5 Synthesis of 2-amino-4H-chromen-4-ylphosphonates catalyzed by $\mathrm{Fe}_{3} \mathrm{O}_{4} @ \mathrm{CS}-\mathrm{SO}_{3} \mathrm{H}$ nanoparticles [92] 


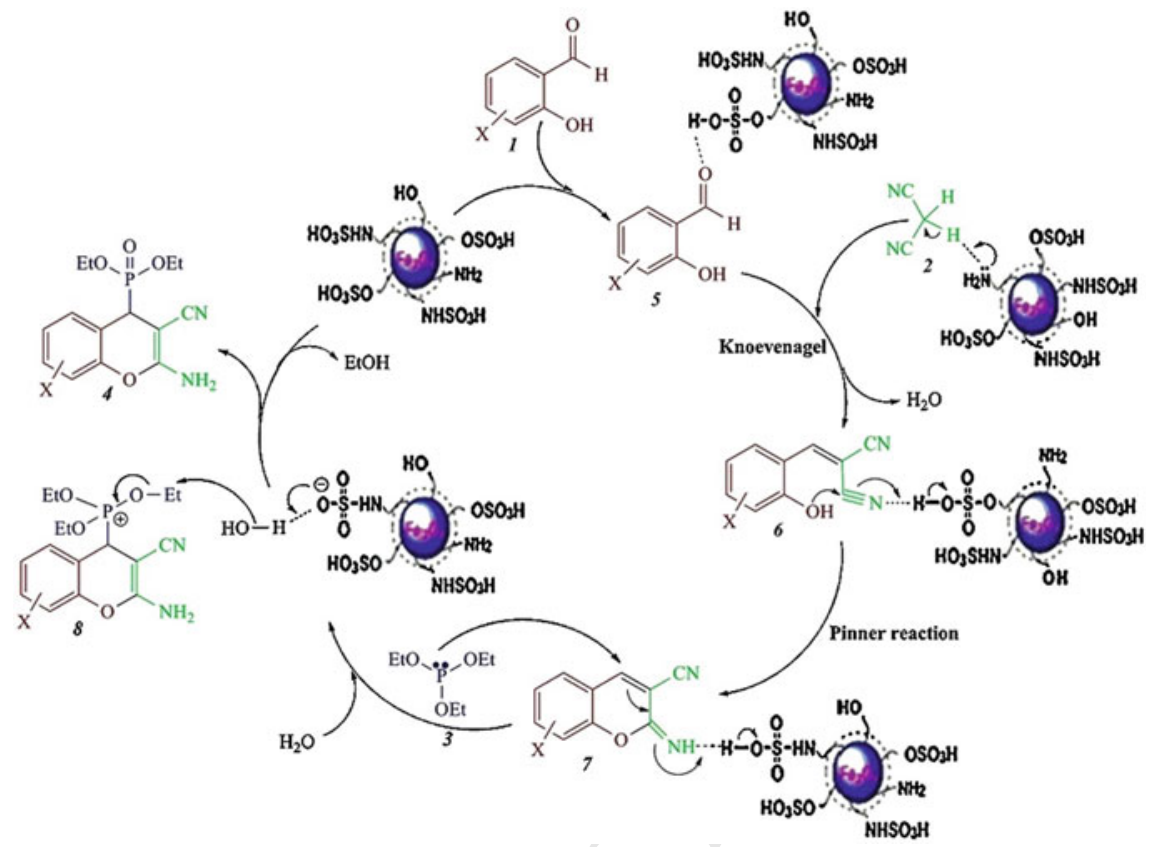

Fig. 8.3 Plausible mechanism for the synthesis of 2-amino- $4 H$-chromen-4-ylphosphonates catalyzed by functionalized magnetite, $\mathrm{Fe}_{3} \mathrm{O}_{4} @ \mathrm{CS}-\mathrm{SO}_{3} \mathrm{H}$ nanoparticles. Reprinted from [92], Copyright 2013, with permission from Elsevier, license no. 4640241387630

\subsubsection{Cross-Coupling Reactions}

The upbringing of d-block transition metals in catalyzed cross-coupling reactions is gaining ground against palladium thanks to their larger abundance than noble metals. The Sonogashira-Hagihara cross-coupling reaction enables the formation of a $\mathrm{C}-\mathrm{C}$ bond between an $\mathrm{sp}^{2}$-carbon halide (aryl or vinyl) and a terminal alkyne [116]. This transformation was initially described with a $\mathrm{Pd}(0)$ catalyst and a $\mathrm{Cu}(\mathrm{I})$ co-catalyst, but $\mathrm{Cu}$ alone $[75,79,120]$ or other transition metals have been reported as efficient catalysts for this transformation ( $\mathrm{Ni} \mathrm{[14,} \mathrm{102,} \mathrm{103],} \mathrm{Fe} \mathrm{[66],} \mathrm{Co} \mathrm{[115]),}$ fueling the important role of abundant metals in $\mathrm{C}-\mathrm{C}$ bond forming reactions. Gaining a better understanding on the physicochemical processes leading to the formation of MNPs is key for the design of nanocatalysts with defined morphology [50, 96], notably when catalyst heterogenization with solid supports such as zeolites, titania, montmorillonite and carbonaceous materials is required. Robustness and catalytic activity of tailor-made nanostructured catalysts outperform in many cases classical ones [90].

$\mathbf{C}(\mathbf{s p})-\mathbf{C}\left(\mathbf{s p}^{2}\right)$ Sonogashira cross-coupling Since synthesis of copper(I) acetylide, the first organometallic copper complex described in 1859 [19], the reactivity of copper toward the activation of terminal alkyne groups has yielded a number of 
interesting transformations for the synthesis of propargylic compounds [33]. The search of catalytic versions is key for exploiting the privileged reactivity of this metal from the point of view of sustainability [36]. Recent reports on the singular $\pi$-activation of alkynes leveraged by zero-valent CuNPs reveal the importance of this coordination in catalysis $[31,96]$.

In this context, the cross-coupling of terminal alkynes and acyl chlorides has been reported by Bhosale et al. using a $\mathrm{Cu} / \mathrm{Cu}_{2} \mathrm{O}$ catalyst prepared from $\mathrm{Cu}(\mathrm{OAc})_{2}$ in onestep under microwave irradiation ( $3 \mathrm{~min}, 600 \mathrm{~W}$ ) in 1,3-propanediol. The as-prepared catalytic material exhibited an irregular morphology that combines tubular domains and spherical particles ranging from 70 to $110 \mathrm{~nm}$ in size (Fig. 8.4) of a mixture of $\mathrm{Cu}(0)$ and $\mathrm{Cu}_{2} \mathrm{O}$ as confirmed by high-resolution XPS analysis [16].

Taking into account the paramount importance that metal traces might have in catalysis, it is crucial to determine their contribution and potential cooperative effects. Firouzabadi et al. described the use of spherical paramagnetic $\mathrm{Fe}_{3} \mathrm{O}_{4} \mathrm{NPs}(<30 \mathrm{~nm}$ in diameter) in ethylene glycol under ligand-free conditions for the SonogashiraHagihara reaction for the synthesis of (hetero)aryl alkynes from terminal alkynes and haloarenes (e.g., heteroaryl bromides, aryl iodides, Scheme 8.6) [44, 45]. In order to ascertain the role of $\mathrm{Fe}_{3} \mathrm{O}_{4}$ NPs as catalyst, the authors determined the traces of $\mathrm{Pd}, \mathrm{Ni}, \mathrm{Cu}$, and $\mathrm{Co}$ present both in the reagents and solvent. Thus, the contamination concerning the above-mentioned metals was found to be $130 \mathrm{ppb} \mathrm{Pd}, 45 \mathrm{ppb} \mathrm{Ni}$, $24 \mathrm{ppb} \mathrm{Cu}$, and $21 \mathrm{ppb} \mathrm{Co}$ for $\mathrm{K}_{2} \mathrm{CO}_{3}$; as well as $20 \mathrm{ppb} \mathrm{Pd}, 33 \mathrm{ppb} \mathrm{Cu}, 27 \mathrm{ppb} \mathrm{Ni}$,

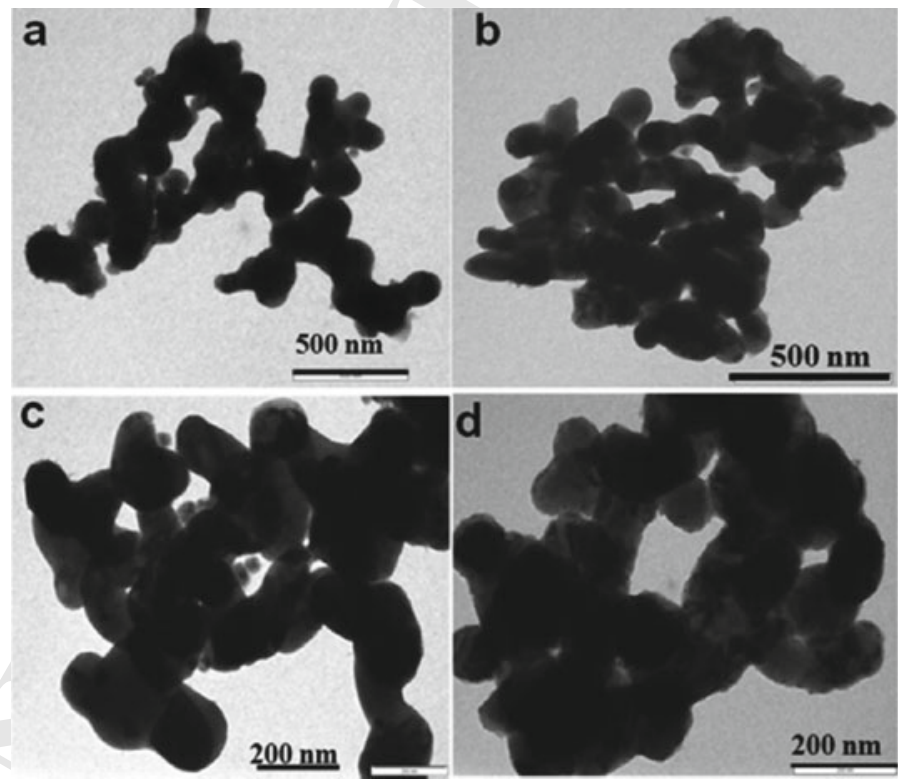

Fig. 8.4 TEM micrographs of $\mathrm{Cu} / \mathrm{Cu}_{2} \mathrm{O}$ NPs. Reproduced with permission from Royal Society of Chemistry 2014, license no. 4639380035278 


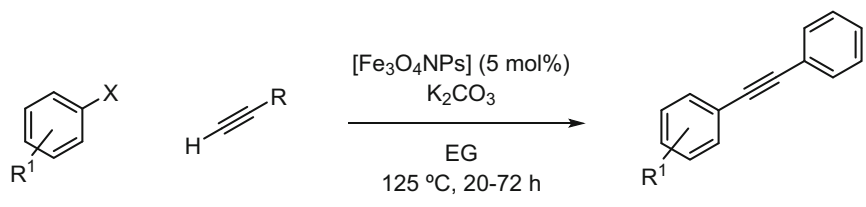

$\mathrm{X}=\mathrm{I}, \mathrm{Br}$

$\mathrm{R}^{1}=4-\mathrm{OMe}, 4-\mathrm{NO}_{2}$, 4-Me, 4- $\mathrm{Br}, 4-\mathrm{OH}, 2-\mathrm{Me}, 2-\mathrm{OMe}$

$\mathrm{R}^{2}=\mathrm{Ph}, 4-\mathrm{MePh}, \mathrm{n}-\mathrm{C}_{6} \mathrm{H}_{13}$

8 examples
Isolated Yield: $76-92 \%$

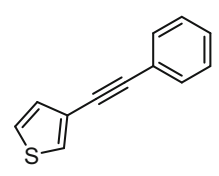

$86 \%$

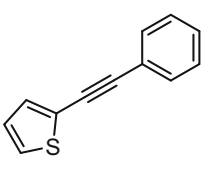

$85 \%$

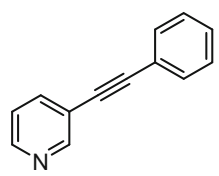

$80 \%$

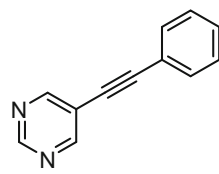

$76 \%$

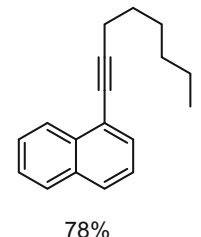

$78 \%$

Scheme 8.6 $\mathrm{Fe}_{3} \mathrm{O}_{4}$ NPs catalyzed Sonogashira-Hagihara coupling reaction in EG [44]

and $24 \mathrm{ppb}$ Co for ethylene glycol by ICP analyses. As catalyst controls, different metal salts [e.g., $\mathrm{Pd}(\mathrm{OAc})_{2}, \mathrm{CuCl}, \mathrm{NiCl}_{2} \mathrm{CoCl}_{2}$ ] at concentrations ranging from 200 to $1500 \mathrm{ppb}$ were tested, but the catalytic activity of $\mathrm{Fe}_{3} \mathrm{O}_{4} \mathrm{NPs}$ at $5 \mathrm{~mol} \%$ loadings proved to be superior [44]. The magnetic properties of $\mathrm{Fe}_{3} \mathrm{O}_{4} \mathrm{NPs}$ allowed an easy catalyst recycling with only an overall $2 \%$ yield decrease after five consecutive runs.

An example of bimetallic nanocatalyst for Sonogashira cross-coupling reaction featuring PdCo NPs supported on graphene has been described by Dabiri et al. [29]. The synthesis of this nanocomposite was carried out following the polyol methodology. In particular, the co-reduction of $\mathrm{PdCl}_{2}$ and $\mathrm{CoCl}_{2}$ was performed in ethylene glycol, which acted as reducing and stabilizing agent for the immobilization of NPs on the 3D graphene support (Fig. 8.5). XPS analysis of the as-prepared nanocomposite revealed the presence of zero-valent $\mathrm{Pd}$ and $\mathrm{Co}$ (binding energies at 335.67 and $341.49 \mathrm{eV}$ corresponding to $\mathrm{Pd} 3 \mathrm{~d}_{5 / 2}$ and $\mathrm{Pd} 3 \mathrm{~d}_{3 / 2}$; as well as 781.53 and $798.16 \mathrm{eV}$ corresponding to Co $2 \mathrm{p}_{3 / 2}$ and Co $2 \mathrm{p}_{1 / 2}$ ), which match the literature values for PdCo alloys. Higher oxidation states, namely $\mathrm{Pd}(\mathrm{II}), \mathrm{Co}(\mathrm{II})$, and $\mathrm{Co}(\mathrm{III})$ were also detected, the latter arising from an oxidation on the NPs surface [29]. The prepared PdCo nanocomposite exhibited high catalytic activity for Sonogashira and Suzuki cross-coupling reactions of aryl halides with terminal alkynes and boronic acids, respectively, in water. Moreover, the catalyst was recycled up to seven times without loss in catalytic activity.

Aluminosilicate-based materials such as montmorillonite are largely used as catalyst supports. Liu et al. have recently described the co-immobilization of $\mathrm{Cu}$ and $\mathrm{Pd}$ on a montmorillonite-chitosan matrix. According to the authors, the resulting bimetallic $\mathrm{CuPd}$ nanocomposite features $\mathrm{Pd}$ coexisting in both $\mathrm{Pd}(0)$ and $\mathrm{Pd}(\mathrm{II})$ valence states, as well as $\mathrm{Cu}$ mainly in its $\mathrm{Cu}(\mathrm{II})$ as determined by XPS. However, the presence of $\mathrm{Cu}(0)$ and $\mathrm{Cu}(\mathrm{I})$ cannot be excluded relying solely on this technique. The as-prepared 


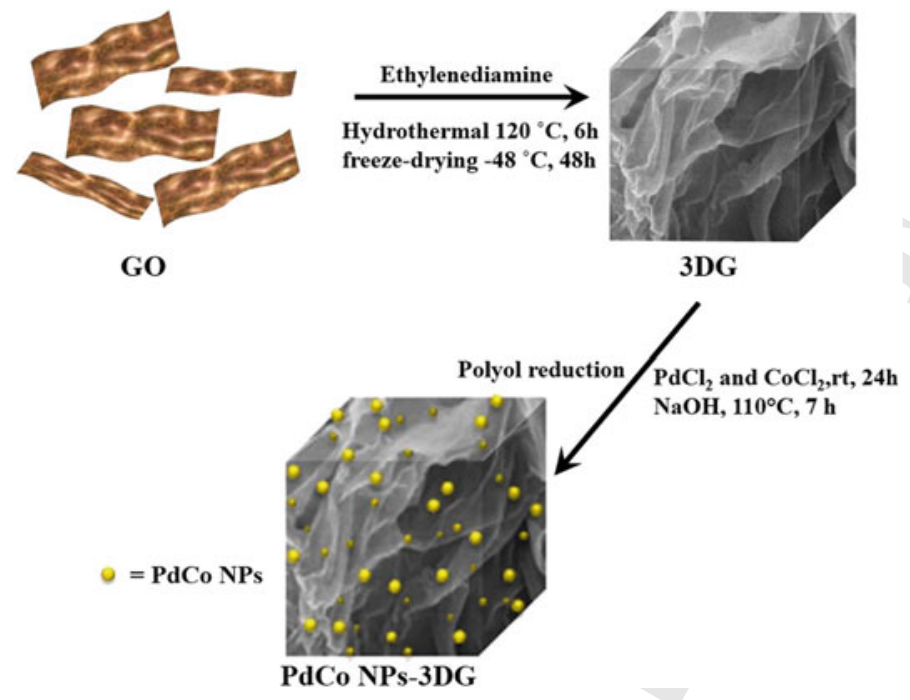

Fig. 8.5 Synthesis of PdCo NPs supported on graphene. Reproduced with permission from Ref. [29]. Copyright 2016 Wiley, license no. 4639270206261

nanocomposite containing spherical PdNPs below $3 \mathrm{~nm}$ in diameter catalyzed Sonogashira couplings of haloarenes and alkynes in 1,2-dimethoxyethane/ $\mathrm{H}_{2} \mathrm{O}$, although $\mathrm{Cu}$ leaching resulted in an activity decrease upon recycling [80].

Alternatively, the stabilization of Pd at higher oxidation states could be achieved via the formation of stable $\mathrm{Pd}-N$-heterocyclic carbene complexes. Yavuz et al. have recently reported Sonogashira cross-coupling reaction catalyzed by in situ generated $\mathrm{Pd}-1 H$-benzo $\left[d\right.$ ] imidazolium complexes [from $\mathrm{Pd}(\mathrm{OAc})_{2}$ and $\mathrm{Cs}_{2} \mathrm{CO}_{3}$ ], and $\mathrm{CuNPs}$ in PEG300 [132]. However, authors did not characterize the catalyst employed.

Suzuki-Miyaura-type cross-coupling During the last years, the controlled synthesis of NiNPs has drawn attention to several research groups, the main challenge being the exclusive preparation of zero-valent nickel nanomaterials due to the facile oxidation of $\mathrm{Ni}(0)$ species. Consequently, the lack of control of nickel oxidation in preformed nanoparticles is a persistent issue, as shown by several authors. Among them, one finds Tilley and coworkers in the synthesis of nickel nanocubes from $\mathrm{Ni}(\mathrm{acac})_{2}$ under $\mathrm{H}_{2}$ [77]; Hyeon's group in the preparation of NiNPs under thermal decomposition [98]; and Zarbin and coworkers in the synthesis of NiNPs following the polyol approach [97]. Chaudret and coworkers published an efficient method for the synthesis of nickel $(0)$ nanorods, from $\left[\mathrm{Ni}(\mathrm{COD})_{2}\right]$ under hydrogen atmosphere [27]. More recently, zero-valent NiNPs were successfully prepared in neat glycerol, without exhibiting any oxide shell on their surface thanks to the low solubility of molecular oxygen in glycerol; these nanocatalysts were, in particular, highly efficient for the semi-hydrogenation of alkynes [105]. However, Ni-based nanoparticles have been scarcely applied in $\mathrm{C}-\mathrm{C}$ cross-coupling reactions. Their efficiency is particularly remarkable when they are formed in situ, as proven by Lipshutz and coworkers using 
NiNPs generated in water in the presence of appropriate surfactants (acting as stabilizers) and the Grignard reagent $\mathrm{MeMgBr}$ to activate the pre-catalyst $\left(\left[\mathrm{NiCl}_{2} \mathrm{~L}_{\mathrm{n}}\right]\right.$, where $\mathrm{L}$ is a (di)phosphine and $n=1$ or 2), which were successfully applied in Suzuki-Miyaura couplings [61]. Simultaneously, Han and coworkers reported Nicatalyzed carbonylative Suzuki-based reactions in PEG (Scheme 8.7) [135], process leading to biaryl ketones, motif present in different types of compounds (drugs, photosensitizers ...). They compared the reactivity between preformed and in situ generated NiNPs, evidencing that those formed in situ were more active, probably because the latter are smaller, showing less aggregation that the preformed ones. Authors carried out control tests (with $\mathrm{Hg}$ and $\mathrm{CS}_{2}$ ) in order to prove the nature of the catalytically active species (in the presence of both additives, the reaction did not work), concluding that the activity observed agrees with a surface-like reactivity.

Preformed NiNPs stabilized by triazole-modified chitosan were active nanocatalysts for Suzuki-Miyaura reactions between aryl halides and phenyl boronic acid derivatives (Scheme 8.8) [59].

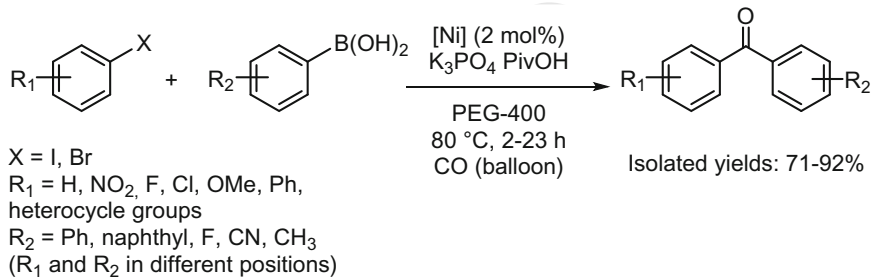

Scheme 8.7 In situ generated NiNPs in PEG-400 applied in carbonylative Suzuki coupling reactions [135]
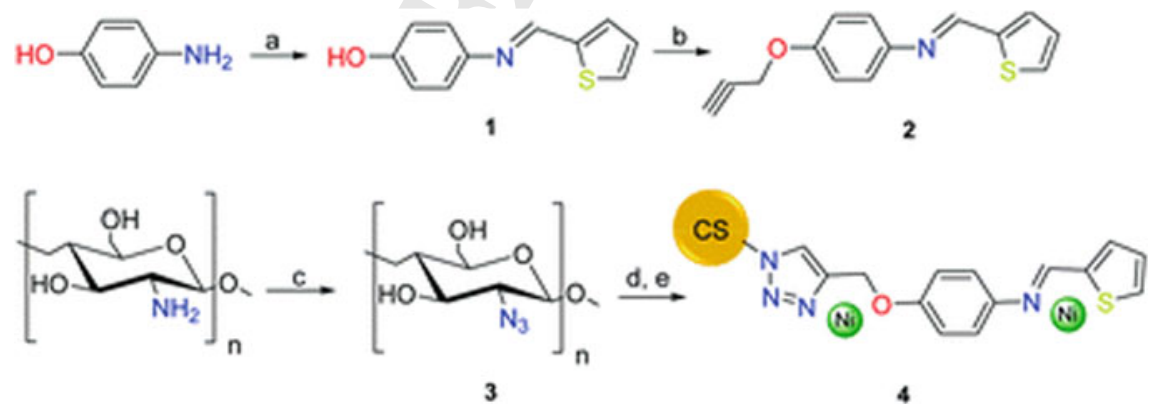

Scheme 8.8 Synthetic path for the synthesis of NiNPs stabilized by modified chitosan: a thiophene2-carbaldehyde, $\mathrm{MeOH}$, reflux, $3 \mathrm{~h}$; b propargyl bromide, $\mathrm{K}_{2} \mathrm{CO}_{3}$, acetone, $50^{\circ} \mathrm{C}, 24 \mathrm{~h}$; c triflyl azide, aqueous $\mathrm{HCl} \cdot \mathrm{NaHCO}_{3}, \mathrm{CuSO}_{4} \cdot 5 \mathrm{H}_{2} \mathrm{O}, \mathrm{MeOH}$, r.t., 5 d; d 2, CuI, DMF/THF (1: 1), r.t., $72 \mathrm{~h} ; \mathbf{e ~} \mathrm{NiCl}_{2} / \mathrm{EtOH}$ solution, 12 h, r.t., then hydrazine hydrate, r.t., 2 h. New journal of chemistry by Center national de la recherche scientifique (France); Royal Society of Chemistry (Great Britain) Reproduced with permission of ROYAL SOCIETY OF CHEMISTRY in the format Book via Copyright Clearance Center, license no. 4639350882762 [59] 

274

Heck-Mizoroki-type cross-coupling Since the pioneering and independent works from Gilman and Lichtenwalter [55], and Kharasch [69] in the 1930s and 1940s, concerning the homocoupling reaction of Grignard reagents promoted by cobalt(II) salts, scarce works were carried out up to the 1990s [21] and references therein. Cobalt complexes have proven their efficiency for the formation of $\mathrm{C}\left(\mathrm{sp}^{2}\right)-\mathrm{C}\left(\mathrm{sp}^{2}\right)$ bonds; particularly, Co-based catalysts are interesting for cross-couplings where alkyl halides are involved, because $\beta$-hydrogen elimination of alkyl intermediates is not favored in contrast to the analogous $\mathrm{Pd}$ and $\mathrm{Ni}$ organometallic species. In the frame of the present contribution, $\mathrm{Co}$ (II) anchored to chitosan-functionalized $\mathrm{Fe}_{3} \mathrm{O}_{4}$ NPs has found applications in Heck- and Sonogashira-type couplings [60]. $\mathrm{Fe}_{3} \mathrm{O}_{4}$ NPs containing chitosan were modified by reaction with methyl salicylate to give amide-phenol groups at their surface, which coordinate $\mathrm{CoCl}_{2}$ (Scheme 8.9).

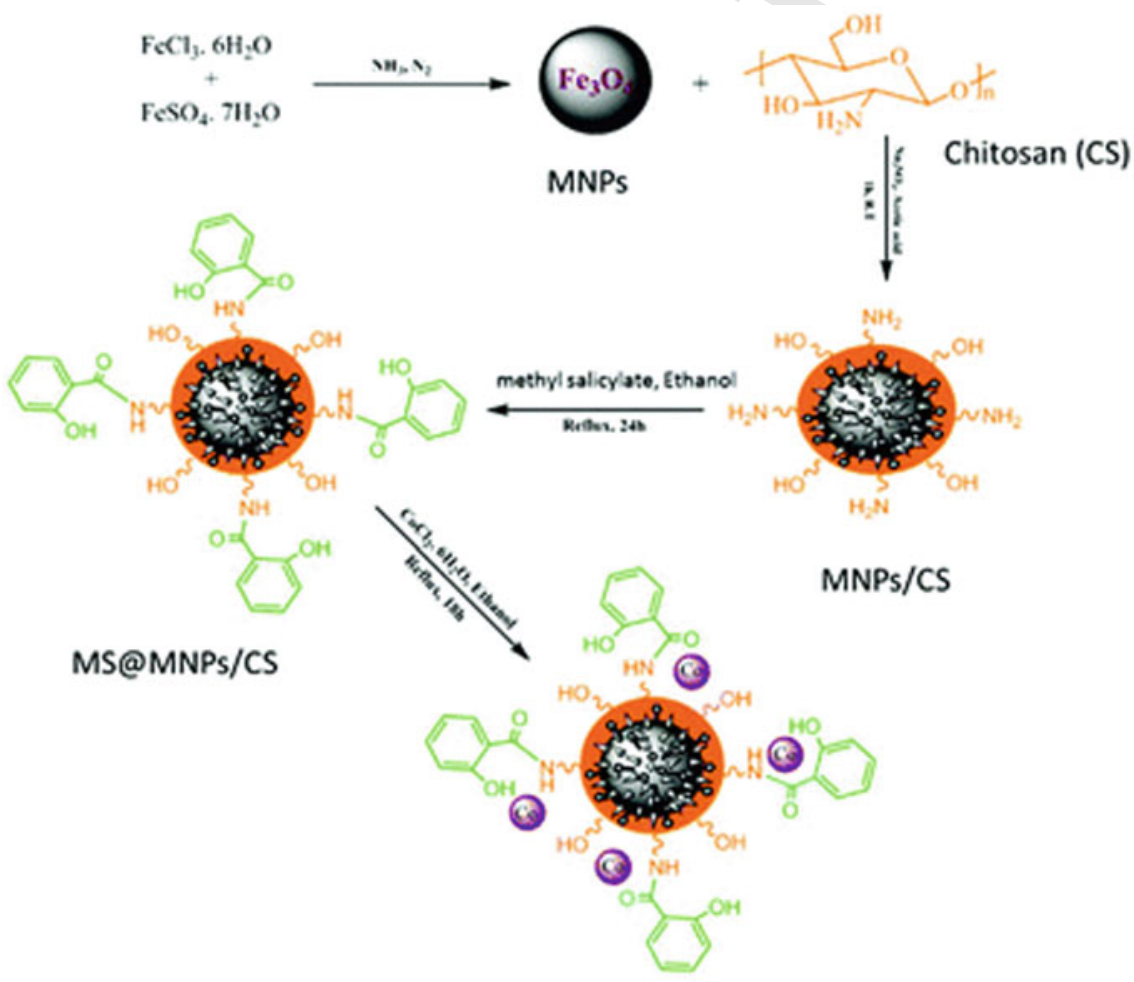

Co·MS@MNPs/CS

Scheme 8.9 Preparation of co-based nanocatalyst immobilized on $\mathrm{Fe}_{3} \mathrm{O}_{4}$ nanoparticles modified by chitosan. Green Chemistry by Royal Society of Chemistry (Great Britain) Reproduced with permission of ROYAL SOCIETY OF CHEMISTRY in the format Book via Copyright Clearance Center, license no. 4639360400827 [60] 
This represents an example of molecular-like catalytic reactivity using functionalized nanoparticles as support. For the Heck-type reaction, the catalyst was efficient for the coupling of aryl halides (chloro, bromo, iodo) with styrene or methyl acrylate using PEG as solvent (Scheme 8.10). In contrast to the non-functionalized $\mathrm{Fe}_{3} \mathrm{O}_{4}$ NPs, the functionalized ones were more active and could be recycled up to five times preserving their efficiency, without metal leaching. The Sonogashira-type coupling between aryl halides (bromo, iodo) and phenylacetylene derivatives gave moderate yields under harsher conditions than those used for the Heck couplings.

Kumada-type cross-coupling Kumada-Tamao-Corriu reaction, coupling between a Grignard reagent and an organic halide, was initially reported using Ni-based catalysts [28, 118]; other efficient systems such as those based on palladium and iron, have proven their efficacy, the main part of them involving molecular catalysts, but more recently copper, nickel, and palladium nanoparticles have been used as well $([63,91]$ and references therein). Iron, representing the second more abundant metal in the Earth's crust, has found interesting applications in $\mathrm{C}-\mathrm{C}$ couplings $[3,12,95]$. The main part of reported works assumes the contribution of molecular intermediate species in the catalytic transformation, but also nanoparticles have been identified for low oxidation states (zero-valent FeNPs should be more stable under catalytic conditions than organometallic $\mathrm{Fe}(0)$ complexes) and it has been postulated that they act as a reservoir of molecular species exhibiting higher oxidation state [10]. Bedford and coworkers studied the reaction of alkyl halides with aryl Grignard compounds catalyzed by in situ generated FeNPs from $\mathrm{FeCl}_{3}$ in the presence of PEG-14000 (Scheme 8.11 and Fig. 8.6) [11]. Authors proved that the Grignard reagent acted as

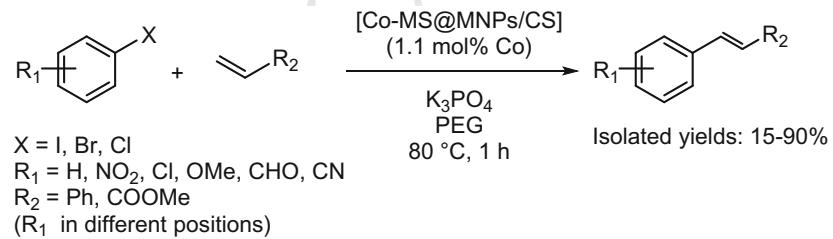

Scheme 8.10 Heck-Mizoroki-type couplings catalyzed by Co(II) supported on functionalized $\mathrm{Fe}_{3} \mathrm{O}_{4}$ nanoparticles (see Scheme 8.9) [60]

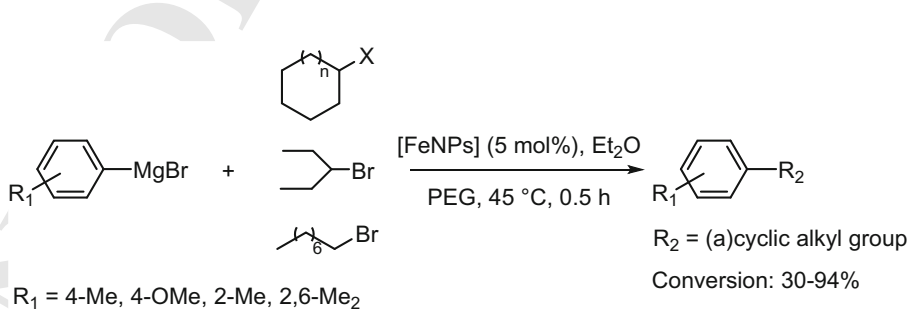

$\mathrm{X}=\mathrm{Cl}, \mathrm{Br}, \mathrm{I}, \mathrm{CH}_{2}-\mathrm{CH}_{2}-\mathrm{Br}$

$\mathrm{n}=0,1,2$

Scheme 8.11 $\mathrm{C}\left(\mathrm{sp}^{2}\right)-\mathrm{C}\left(\mathrm{sp}^{3}\right)$ cross-coupling catalyzed by FeNPs stabilized by PEG [11] 


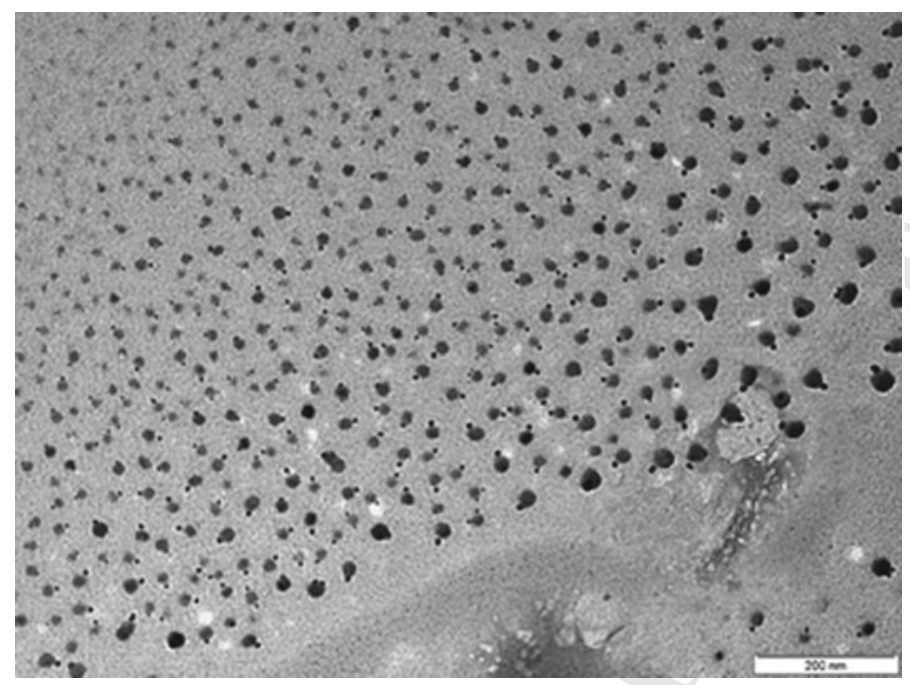

Fig. 8.6 TEM image corresponding to FeNPs generated in situ from $\mathrm{FeCl}_{3}$ in the presence of 1,6-bis(diphenylphosphino)hexane with 4- $\mathrm{MeC}_{6} \mathrm{H}_{4} \mathrm{MgBr}$. Reproduced with permission of ROYAL SOCIETY OF CHEMISTRY in the format Book via Copyright Clearance Center, license no. 4640081165587 [11]

reducing agent. Preformed FeNPs/PEG (diameter in the range 7-13 nm, determined by TEM) afforded the same reactivity as those formed in situ.

\subsection{Carbon-Heteroatom Bond Formation}

The activation of C-halogen bonds has been overwhelmingly used in the functionalization of arenes. Since the discovery of Ullmann's coupling in 1901, copper has been one of the most used earth-abundant metals in both $\mathrm{C}-\mathrm{C}$ and $\mathrm{C}$-heteroatom couplings (original paper of Ullmann: [125]; recent reviews: [13, 94, 108]). However, many applications of this reactivity are especially limited due to the use of hazardous solvents such as DMF and DMSO. A lot of interest has been put into transforming this reactivity into greener approaches. In this context, considerable efforts have been recently developed in nanocatalytic systems capable of working in friendly environmental conditions [67, 127], polyols being alternative solvents of interest [39].

This strategy has been successfully applied in a wide range of $\mathrm{C}-\mathrm{N}$ couplings using many different nitrogen-based reagents. Kidwai and coworkers applied preformed unsupported CuNPs in the $N$-arylation of aryl halides with anilines using PEG400 as solvent (Scheme 8.12) [73]. A large scope of aniline derivatives and also $\mathrm{NH}$ heterocycles was carried out. 


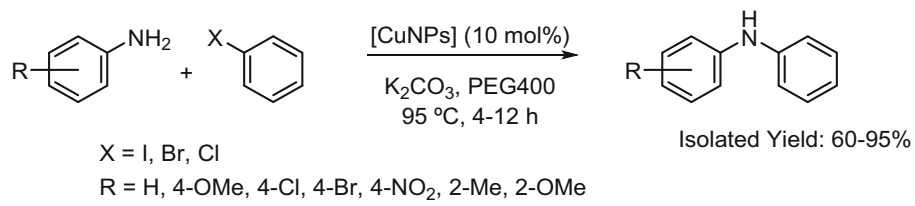

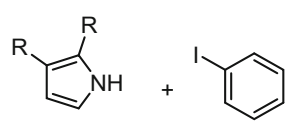<smiles>[R]c1cc[nH]c1[R]</smiles><smiles>[R]c1nc[nH]c1[R]</smiles><smiles>[R]c1nc[nH]c1[R]</smiles>

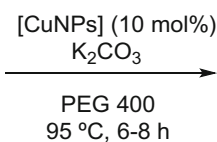<smiles>c1cc[nH]c1</smiles><smiles>[R]c1ccn(-c2ccccc2)c1[R]</smiles>

Isolated Yield: $89-91 \%$

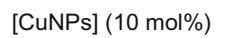

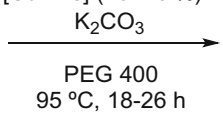<smiles>[R]c1ncn(-c2ccccc2)c1[R]</smiles>

Isolated Yield: $69-95 \%$<smiles>Cc1cnc[nH]1</smiles>

Scheme 8.12 CuNPs catalyzed C-N cross-couplings of anilines and NH heterocycles with aryl halides in PEG400 [73]

Graphene oxide functionalized with carboxamide groups (f-GO) was an efficient support to coordinate $\mathrm{Cu}(\mathrm{II})$ salts and further reducing them to give CuNPs immobilized on the solid. This CuNPs on $\mathrm{f}-\mathrm{GO}$ were then treated with $\mathrm{Fe}_{3} \mathrm{O}_{4}$ nanoparticles leading to a magnetic catalytic material, which enhanced the catalyst recyclability (Fig. 8.7) [112].

The as-prepared heterogenized nanocatalyst was applied to Ullmann-type coupling for the synthesis of $\mathrm{N}$-aryl amines using a deep eutectic solvent (choline chloride:glycerol =1:2) (Scheme 8.13). Authors compared the efficiency of this catalytic system with other CuNPs, both supported and unsupported, concluding that their catalyst led to higher yields under smoother conditions. However, the recycling was moderate (up to 3 times without loss of activity).

The work of our group on the preparation of small CuNPs $\left(d_{\text {mean }}=1.7-2.4 \mathrm{~nm}\right)$ in glycerol from the reduction of $\mathrm{Cu}(\mathrm{II})$ and $\mathrm{Cu}(\mathrm{I})$ precursors with $\mathrm{PVP}$ as stabilizer and under low pressure of $\mathrm{H}_{2}$ ( $3 \mathrm{bar}$ ) avoided the formation of oxidized by-products coming from the solvent (Fig. 8.8). This approach represents the first report toward the synthesis of well-defined and stable CuNPs by a bottom-up strategy thanks to the low solubility of $\mathrm{O}_{2}$ in this medium, circumventing the formation of oxide shells [31]. 


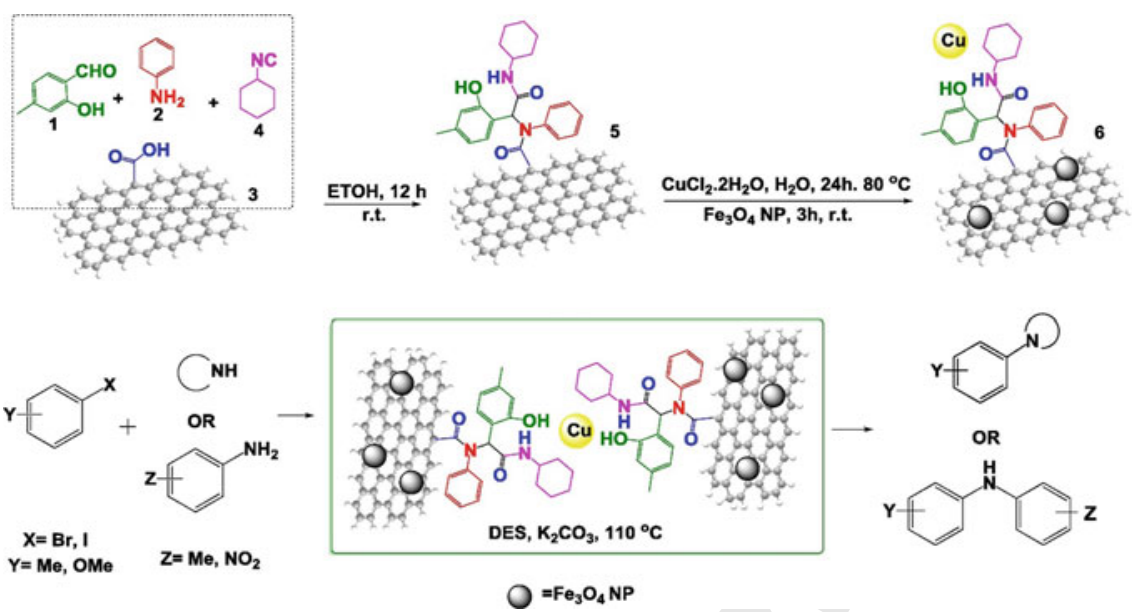

Fig. 8.7 Illustration of the synthesis of CuNPs immobilized on f-GO containing $\mathrm{Fe}_{3} \mathrm{O}_{4}$ NPs (top) with the application in $\mathrm{C}-\mathrm{N}$ bond formation processes (bottom). Reprinted from [112], Copyright 2018, with permission from Elsevier, license no. 4640121432056

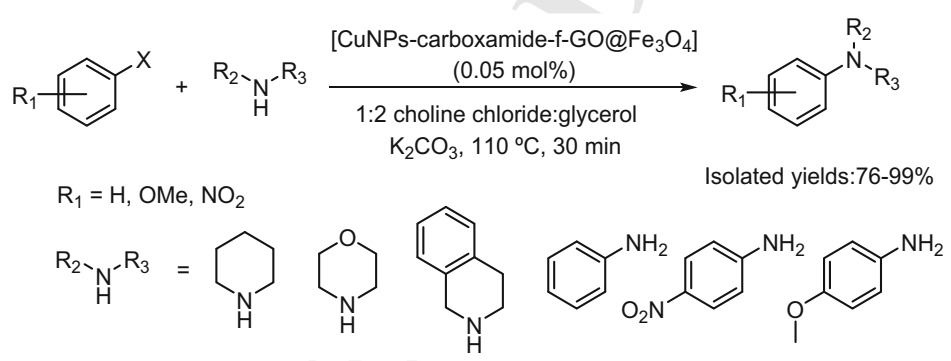

Scheme 8.13 CuNPs immobilized on a magnetic-modified graphene oxide (see Fig. 8.7) catalyzed $\mathrm{C}-\mathrm{N}$ couplings of secondary amines and anilines [112]

$\mathrm{CuA}$ nanoparticles were successfully applied in $\mathrm{C}-\mathrm{N}$ couplings and in the synthesis of propargyl amines through different strategies, such as cross-dehydrogenative couplings and multicomponent reactions, both $\mathrm{A}^{3}$ (aldehyde-alkyne-amine) and $\mathrm{KA}^{2}$ (ketone-alkyne-amine) (Scheme 8.14). Authors carried out spectroscopic monitoring (UV-vis and FTIR analyses) concluding that the $\mathrm{C}-\mathrm{N}$ coupling follows a surface reactivity, without formation of $\mathrm{Cu}(\mathrm{I})$ molecular species, like phenylethynylcopper(I), which would be poisoned by the presence of amines.

The selection of alternative aldehydes bearing heteroatoms in position 2 of the ring (e.g., 2-aminobenzaldehyde, 2-hydroxybenzaldehyde and 2-pyridinecarbaldehyde) provided a direct entry to the synthesis of heterocycles, namely indolizines, benzofurans and quinolines via a $\mathbf{C u A}$-catalyzed $\mathrm{A}^{3}$-cycloisomerization tandem processes (Scheme 8.15). 


$$
[\mathrm{Cu}]_{\text {precursor }} \underset{\begin{array}{l}
\mathrm{M}(\mathrm{PVP})=10,000 \mathrm{~g} / \mathrm{mol} \\
\mathrm{Cu} / \mathrm{monomer}=1 / 20 \\
{[\mathrm{Cu}]=10^{-2} \mathrm{molL}^{-1}}
\end{array}}{\stackrel{\mathrm{H}_{2}(3 \mathrm{bar})}{\text { overnight }}} \mathrm{Cu} \mathrm{NPs}
$$

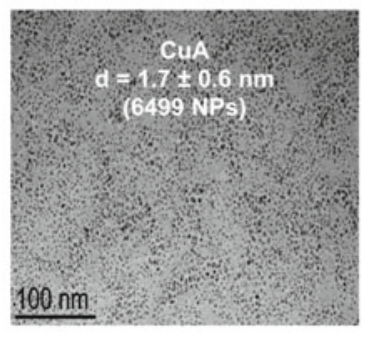

precursor: $\left[\mathrm{Me}_{2}^{\mathrm{Me}_{2}}\right.$

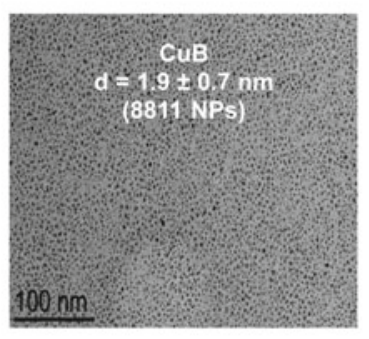<smiles>Cc1cc(C)c(Cl)c(C)c1</smiles>

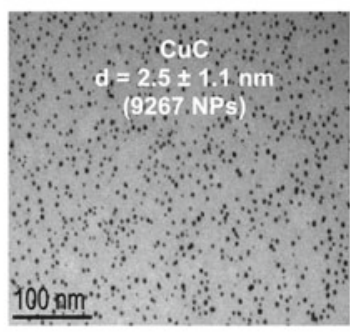

CuOAc

Fig. 8.8 Synthesis of CuNPs in glycerol from different copper precursors stabilized by the polymer PVP (top) and the corresponding TEM images of the different nanoparticles (bottom). Adapted with permission from [31], Copyright 2017 Wiley, license no. 4640130742799

Moreover, Shah et al. have recently reported the $\mathrm{A}^{3}$-coupling reaction for the synthesis of propargylamines and pyrrolo[1,2-a]quinolines using a heterogenized $\mathrm{Cu}$ catalyst (CuNPs@ZnO-polythiophene) at low catalyst loadings (Scheme 8.16). Notably, the cyclization only takes place in an intramolecular fashion and no $\mathrm{Cu}$ leaching was detected in the EG reaction medium after catalyst filtration (ICP analyses).

Preformed $\mathrm{Cu}_{2} \mathrm{O}$ nanoparticles (mean diameter: ca. $5 \mathrm{~nm}$, Fig. 8.9) were applied in the coupling between iodoaryl derivatives and different nitrogen-based reagents, such as aryl and alkyl amines, but also aqueous ammonia, in glycerol [23]. This nanocatalyst was also efficient for the synthesis of thioethers through $\mathrm{C}-\mathrm{S}$ couplings.

This nanocatalyst has also been applied for the activation of terminal alkyne groups toward azide-alkyne cycloaddition reaction (CuAAC) in glycerol (Scheme 8.17) [23].

Furthermore, Sharghi and Aberi reported the application of $\mathrm{Cu}_{2} \mathrm{O}$ NPs in the synthesis of indazole derivatives through a three-component strategy in PEG300 (Scheme 8.18) [114].

$\mathrm{Cu}$-based catalysts in polyol medium have also found interesting applications in $\mathrm{C}-\mathrm{S}$ bond formation processes, as proved by our group using $\mathrm{Cu}_{2} \mathrm{O}$ nanoparticles [23]. Primo, García, and coworkers reported the synthesis of $\mathrm{Cu}$-based nanoparticles stabilized by chitosan, mainly constituted of $\mathrm{Cu}(0)$ but surrounded by a thin layer 
8 Earth-Abundant D-Block Metal Nanocatalysis for Coupling ...

a) Synthesis of amines and anilines<smiles>[X]c1ccc(C([R])[R])cc1</smiles><smiles>[R][R]([H])N([R])c1ccc([R])cc1</smiles>

15 products

Isolated yield: $69-96 \%$<smiles>CN=[Cr]</smiles>

$+\operatorname{amine}$ $100^{\circ} \mathrm{C}, 12 \mathrm{~h}$

$\mathrm{X}=\mathrm{I}, \mathrm{Br}$

$\mathrm{R}^{1}=\mathrm{H}, \mathrm{OMe}, \mathrm{NO}_{2}, \mathrm{CN}$

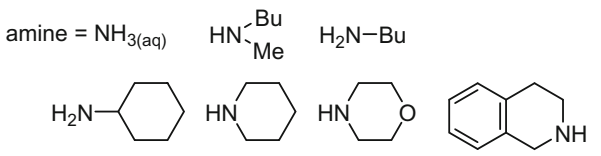

3 products

Isolated yield: $70-93 \%$

b) Cross-dehydrogenative coupling catalyzed by CuA NPs in glycerol<smiles>[R]C#C[CH-][R]</smiles>

[CuA NPs] (1 mol\%) 2 equiv. TBHP glycerol $100{ }^{\circ} \mathrm{C}, 2 \mathrm{~h}$

$\mathrm{R}^{1}=\mathrm{Ph}, 4-\mathrm{CH}_{3}-\mathrm{C}_{6} \mathrm{H}_{4}, 4-\mathrm{COOCH}_{3}-\mathrm{C}_{6} \mathrm{H}_{4}, \mathrm{C}_{5} \mathrm{H}_{11}$ $\mathrm{R}^{1}=\mathrm{H}, 4-\mathrm{Br}, 3-\mathrm{CH}_{3}$

$$
\mathrm{n}=0,1
$$

c) $A^{3}$ coupling catalyzed by CuA NPs in glycerol

$$
\mathrm{R}^{1} \equiv+\mathrm{R}^{2} \stackrel{\mathrm{O}}{=}+\text { amine } \frac{[\text { CuA NPs] }(2 \mathrm{~mol} \%)}{\begin{array}{c}
\text { glycerol } \\
100^{\circ} \mathrm{C}, 12 \mathrm{~h}
\end{array}}
$$

$\mathrm{R}^{1}=\mathrm{Ph}, 4-\mathrm{CH}_{3}-\mathrm{C}_{6} \mathrm{H}_{4}, 4-\mathrm{COOCH}_{3}-\mathrm{C}_{6} \mathrm{H}_{4}, \mathrm{C}_{5} \mathrm{H}_{11}, 4-\mathrm{F}-\mathrm{C}_{6} \mathrm{H}_{4}$ $\mathrm{R}^{2}=\mathrm{Ph}, 4-\mathrm{CH}_{3}-\mathrm{C}_{6} \mathrm{H}_{4}, 4-\mathrm{Br}-\mathrm{C}_{6} \mathrm{H}_{4}, 4-\mathrm{CF}_{3}-\mathrm{C}_{6} \mathrm{H}_{4}, \mathrm{Cy}$

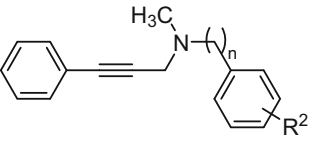

7 products

Isolated yield: $72-91 \%$

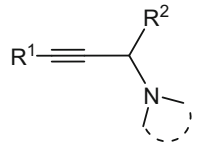

12 products $A^{3}$ Isolated yield: $74-90 \%$

d) CuA-catalyzed $K A^{2}$ multicomponent processes

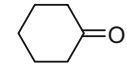<smiles>CCCCC(=O)CC</smiles>

$\mathrm{X}=\mathrm{O}, \mathrm{CH}_{2}$

$\mathrm{R}^{1}=\mathrm{Ph}, \mathrm{C}_{5} \mathrm{H}_{11}$
[CuA NPs] (10 mol\%)

$10 \mathrm{~mol} \% \mathrm{Ti}(\mathrm{OiPr})_{4}$ glycerol $100{ }^{\circ} \mathrm{C}, 12 \mathrm{~h}$

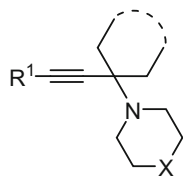

4 products $\mathrm{KA}^{2}$

Isolated yield: $66-82 \%$

Scheme 8.14 CuA NPs catalyzed C-N couplings and multicomponent reactions [31] 
a) Synthesis of indolizines

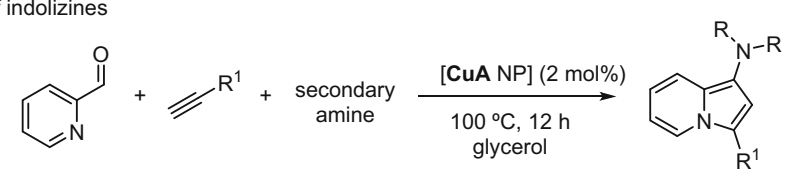

$\mathrm{R}^{1}=\mathrm{Ph}, \mathrm{C}_{5} \mathrm{H}_{11}$

amine: $\mathrm{HN}_{-\mathrm{Me}}^{-\mathrm{Bu}}$
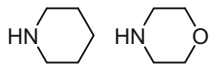

4 examples

Isolated yields: $87-91 \%$

b) Synthesis of benzofurans

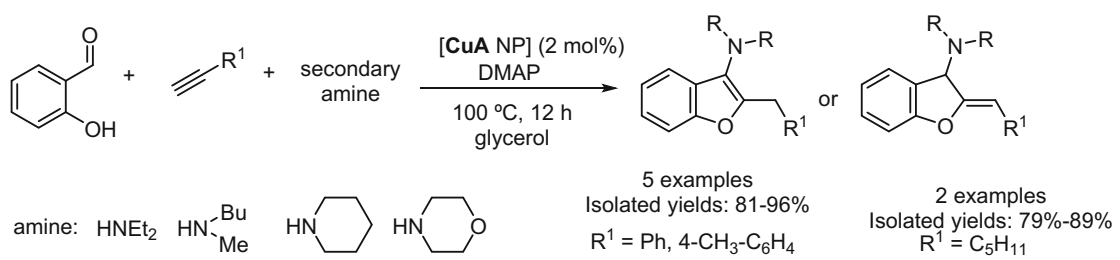

c) Synthesis of quinolines<smiles>[R]C#C</smiles>

$\mathrm{R}^{1}=\mathrm{Ph}, 4-\mathrm{CH}_{3}-\mathrm{C}_{6} \mathrm{H}_{4}$

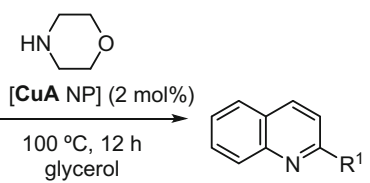

2 examples

Isolated yields: $81 \%-88 \%$

Scheme 8.15 Synthesis of indolizines, benzofurans, and quinolines catalyzed by CuA NPs in glycerol [31]

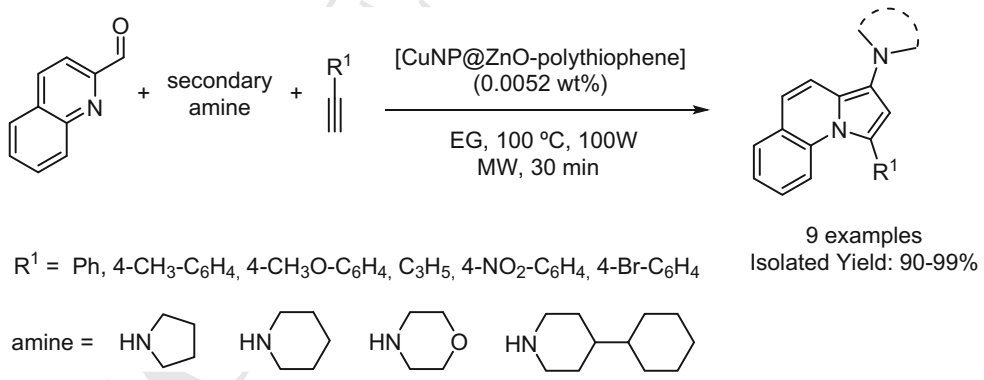

Scheme 8.16 CuNPs@ZnO-polythiophene catalyzed synthesis of pyrrolo[1,2-a]quinolines in EG under microwave irradiation [113] 
8 Earth-Abundant D-Block Metal Nanocatalysis for Coupling ...

a)

$$
\mathrm{Cu}(\mathrm{OAC})_{2}+\underbrace{\stackrel{\mathrm{H}_{2}(3 \mathrm{bar})}{\text { glycerol, } 100{ }^{\circ} \mathrm{C}}}_{\substack{\mathrm{M}(\mathrm{PVP})=10,000 \mathrm{~g} / \mathrm{mol} \\ \mathrm{Cu} / \mathrm{monomer}=1 / 20}} \mathrm{Cu}_{2} \mathrm{O} \mathrm{NPs}
$$
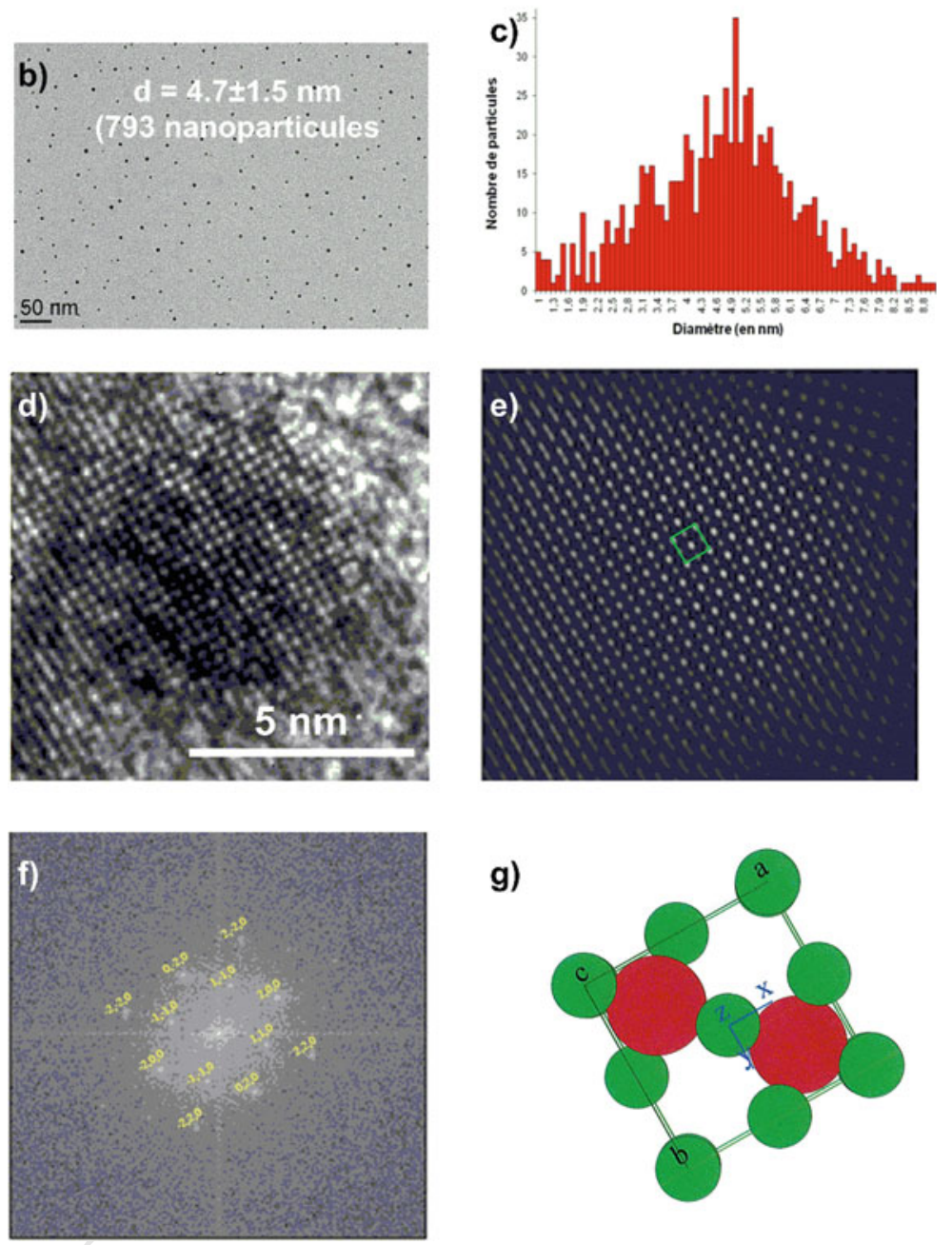

g)

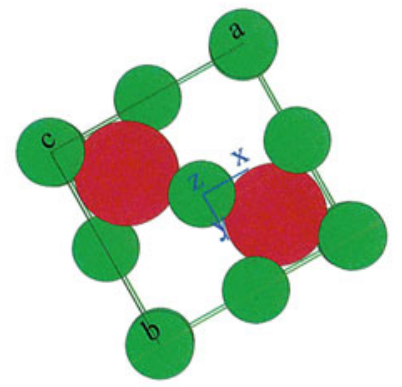

Fig. 8.9 Synthesis of $\mathrm{Cu}_{2} \mathrm{O}$ NPs in glycerol and characterization after isolation at solid state and re-dispersion in glycerol. a Synthesis scheme; b TEM micrograph in glycerol; c size distribution histogram; $\mathbf{d}$ HR-TEM micrograph of one single particle of $\mathrm{Cu}_{2} \mathrm{O}$; e electronic diffraction spots by fast Fourier transform of a single particle; $\mathbf{f}$ filtered image showing the zone axis [ $\left[\begin{array}{ll}0 & 1\end{array}\right]$; $\mathbf{g}$ cartoon of $\mathrm{Cu}_{2} \mathrm{O}$ cubic structure. Adapted with permission from [23], Copyright 2014 Wiley, license no. 4640200545968 


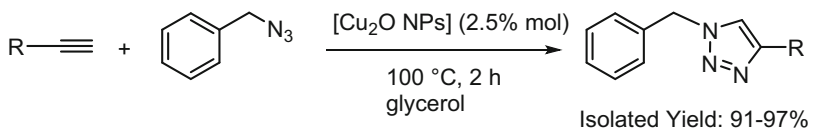

$\mathrm{R}=\mathrm{Ph}, \mathrm{Cy}, \mathrm{n}-\mathrm{Bu}, \mathrm{t}-\mathrm{Bu},\left(\mathrm{CH}_{2}\right)_{3}-\mathrm{CH}_{2}-\mathrm{OH}, \mathrm{CH}_{2} \mathrm{CH}_{2}-\mathrm{OH}$,

$\left(\mathrm{CH}_{3}\right)_{2} \mathrm{C}-\mathrm{OH},\left(\mathrm{CH}_{2}\right)_{5}-\mathrm{CH}_{2} \mathrm{OH}, \mathrm{CH}_{2}-\mathrm{NMe}_{2}$,

Scheme 8.17 $\mathrm{Cu}_{2} \mathrm{O}$ NPs catalyzed azide-alkyne cycloaddition in glycerol [23]

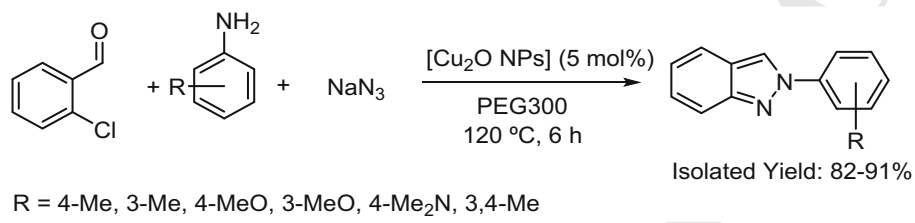

Scheme 8.18 $\mathrm{Cu}_{2} \mathrm{O}$ nanoparticles catalyzed the synthesis of $2 H$-indazoles [114]

Scheme 8.19 CuNPs

stabilized by chitosan applied in $\mathrm{C}-\mathrm{S}$ couplings [47] of copper oxides as proven by XPS [47]. This nanocatalyst was applied in the C$\mathrm{S}$ coupling of aryl halides and thiophenol, being more active for iodo than bromo and chloro arenes, for the latter ones they were only active for aryl halides containing electron withdrawing substituents (Scheme 8.19). Authors observed that halide anions released to the medium during the catalytic reaction can act as poison for CuNPs, in addition to promoting metal leaching.

Generally speaking, $\mathrm{C}-\mathrm{O}$ couplings are more challenging reactions mainly due to the limited functional compatibilities and the need of activated substrates [76, 117]. Besides, the use of polyol medium adds another difficulty because the solvent can compete with the substrate. In this frame, Biegi and Ghiasbeigi have recently reported the synthesis and full characterization of functionalized magnetite with isonicotinic acid with the aim of coordinating $\mathrm{Cu}(\mathrm{I})$ precursors (Fig. 8.10) [51]. The resulting catalytic material was efficiently applied to the synthesis of phenol and aniline derivatives (TOF up to $4494 \mathrm{~h}^{-1}$ ), using a mixture of PEG and water as solvent (PEG: $\mathrm{H}_{2} \mathrm{O}=2: 1$ ) (Scheme 8.20). The catalytic phase was recycled up to 5 times with slight loss of yield, although the $30 \%$ copper loss reported by the authors after the fourth run was substantial ( $\mathrm{Cu}$ content of catalyst before use: 57,037.8 ppm; after 4th run: 40,297.3 ppm).

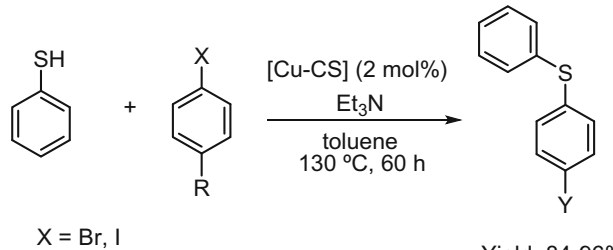

Yield: $84-96 \%$ 

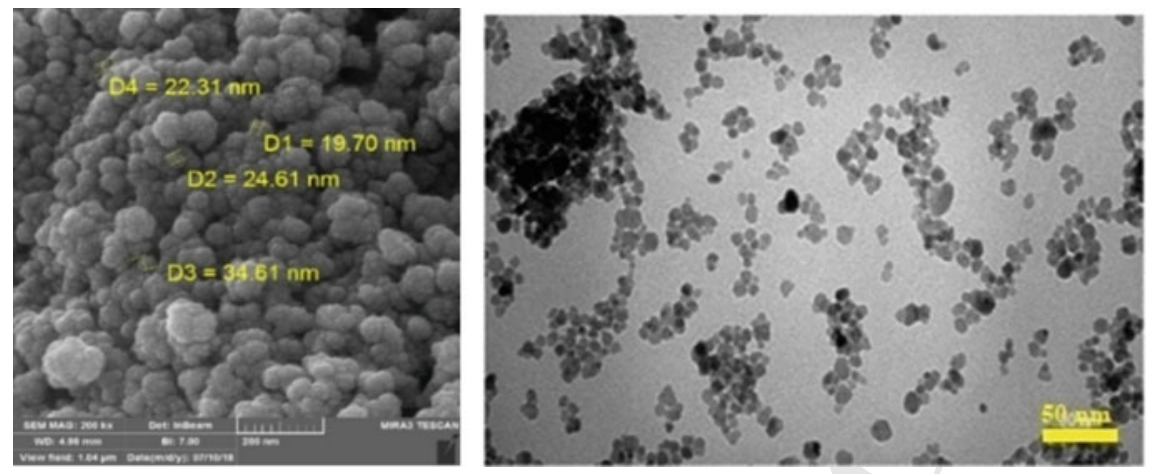

Fig. 8.10 SEM (left) and TEM (right) images of $\mathrm{Cu}(\mathrm{I})$ grafted to $\mathrm{Fe}_{3} \mathrm{O}_{4}$ modified by isonicotinic groups. Reprinted with permission from [51], Copyright 2019 Wiley, license no. 4640160235060

Scheme 8.20 Synthesis of phenols catalyzed by $\mathrm{Cu}$-based catalyst supported on modified $\mathrm{Fe}_{3} \mathrm{O}_{4}[51]$
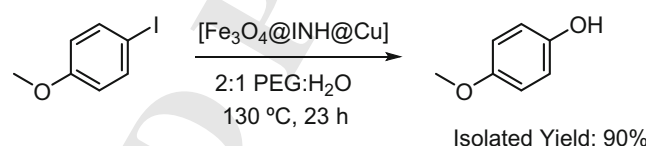

\subsection{Conclusions and Outlook}

This chapter describes the use of nanocatalysts from Earth-abundant metals in polyol media applied in $\mathrm{C}-\mathrm{C}$ and $\mathrm{C}$-heteroatom coupling reactions. Despite the interesting reports mentioned in this contribution, nanocatalysis based on d-block transition metals in polyols is still in its infancy. This is an exponentially growing research field that exploits the non-innocent physicochemical properties of polyols as reducing, stabilizing, and dispersing agents in the quest for tailor-made nanocatalysts and nanocomposites with enhanced properties as compared to classical ones. In the framework of the development of greener and more sustainable processes, $\mathrm{Cu}, \mathrm{Ni}$, $\mathrm{Co}$, and $\mathrm{Fe}$ nanocatalysts in polyol media represent key alternatives to overcome the dependence on the scarcity of noble metals in use currently for both academic and industrial purposes.

The Lewis acidity properties of 3d-transition metals confer them suitable properties as (co)catalysts to effect new transformations by means of (i) Lewis acid base-adduct formation, thereby accelerating slow elementary steps, (ii) pKa of the reaction modulation (e.g., release of a Brønsted acid, proton transfer processes), or (iii) activating the catalyst precursors or off-cycle catalyst species by tuning its coordination sphere by anion abstraction. This chapter describes the reports on $\mathrm{Ni}, \mathrm{Cu}$, and Fe Lewis acid mediated transformations in polyol medium, but contributions from other abundant metals will surely appear in the literature in the years to come.

On the other hand, the abundance and redox properties of 3d-metal-oxide-based materials confer them large applicability as supports for catalysts. In particular, the 
magnetic properties of $\mathrm{Fe}_{2} \mathrm{O}_{3}$ and $\mathrm{Fe}_{3} \mathrm{O}_{4}$ as supports enable the recovery of the prepared composite materials. For instance, the use of such supports for the preparation of heterogenized $\mathrm{Pd}$ catalysts for $\mathrm{C}-\mathrm{C}$ cross-coupling reactions and hydrogenations in polyol medium has been widely reported (for selected articles, see: [37, 52, 53, $81,126,137])$. Other supports based on 3d-transition metals such as $\mathrm{TiO}_{2}$ [93], $\mathrm{CuO}$ [25], and $\mathrm{ZnO}$ [113] have also been used for the same purpose. This heterogenization strategy efficiently enables the recoverability of the catalytic materials by magnetic separation, and also in some cases, the enhancement of TON is observed due to the synergy between catalyst and support. Furthermore, polymetallic systems merit further studies to exploit the cooperative effects between active metal centers in polyol medium [32]. The intrinsic properties of polyols in terms of favoring 3D organization via supramolecular interactions, their suitable oxidation potentials for the reduction of transition metal salts and organometallic complexes, as well as their dispersing abilities via solvation interactions, which often trigger an activity increase, confer them unique properties in nanocatalysis.

From a structural point of view, $3 \mathrm{~d}$-metals based-species present several oxidation states, often leading to paramagnetic intermediates of challenging elucidation. Given the specificity developed by nature in biocatalyzed transformations involving $3 \mathrm{~d}-$ transition metals and the demonstrated efficiency of nanocatalysts discussed herein (e.g., Cu NPs for Sonogashira and C-heteroatom couplings, Ni NPs for Suzuki, Co NPs for Heck-Mizoroki, Fe NPs for Kumada-like couplings ...), the fundamental and applied research in this field foresees new reactivities and deep mechanistic insights taking advantage of the cutting-edge in operando techniques available nowadays.

\section{References}

1. Adil SF, Assal ME, Khan M, Al-Warthan A, Siddiqui MRH, Liz-Marzán LM (2015) Biogenic synthesis of metallic nanoparticles and prospects toward green chemistry. Dalton Trans 44(21):9709-9717. https://doi.org/10.1039/C4DT03222E

2. Ai W, Zhong R, Liu X, Liu Q (2019) Hydride Transfer reactions catalyzed by cobalt complexes. Chem Rev 119(4):2876-2953. https://doi.org/10.1021/acs.chemrev.8b00404

3. Alice W, Axel Jacobi von W (2013) Iron(0) nanoparticle catalysts in organic synthesis. Curr Org Chem 17(4):326-335. https://doi.org/10.2174/1385272811317040003

4. Alig L, Fritz M, Schneider S (2019) First-row transition metal (de)hydrogenation catalysis based on functional pincer ligands. Chem Rev 119(4):2681-2751. https://doi.org/10.1021/ acs.chemrev.8b00555

5. An K, Alayoglu S, Ewers T, Somorjai GA (2012) Colloid chemistry of nanocatalysts: a molecular view. J Colloid Interface Sci 373(1):1-13

6. Anastas P, Eghbali N (2010) Green chemistry: principles and practice. Chem Soc Rev 39(1):301-312. https://doi.org/10.1039/B918763B

7. Anastas PT, Kirchhoff MM, Williamson TC (2001) Catalysis as a foundational pillar of green chemistry. Appl Catal A 221(1):3-13. https://doi.org/10.1016/S0926-860X(01)00793-1

8. Anastas PT, Zimmerman JB (2003) Peer reviewed: design through the 12 principles of green engineering. Environ Sci Technol 37(5):94A-101A. https://doi.org/10.1021/es032373g

9. Astruc D (2008) Nanoparticles and catalysis. Wiley 
10. Bedford RB (2015) How low does iron go? Chasing the active species in fe-catalyzed crosscoupling reactions. Acc Chem Res 48(5):1485-1493. https://doi.org/10.1021/acs.accounts. $5 b 00042$

11. Bedford RB, Betham M, Bruce DW, Davis SA, Frost RM, Hird M (2006) Iron nanoparticles in the coupling of alkyl halides with aryl Grignard reagents. Chem Commun 13:1398-1400. https://doi.org/10.1039/b601014h

12. Bedford RB, Brenner PB (2015) The development of iron catalysts for cross-coupling reactions. In: Bauer E (ed) Iron catalysis II. Springer International Publishing, Cham, pp $19-46$

13. Beletskaya IP, Cheprakov AV (2004) Copper in cross-coupling reactions: the post-Ullmann chemistry. Coord Chem Rev 248(21):2337-2364. https://doi.org/10.1016/j.ccr.2004.09.014

14. Beletskaya IP, Latyshev GV, Tsvetkov AV, Lukashev NV (2003) The nickel-catalyzed Sonogashira-Hagihara reaction. Tetrahedron Lett 44(27):5011-5013. https://doi.org/10.1016/ S0040-4039(03)01174-2

15. Beller M (2019) Introduction: first row metals and catalysis. Chem Rev 119(4):2089. https:// doi.org/10.1021/acs.chemrev.9b00076

16. Bhosale MA, Sasaki T, Bhanage BM (2014) A facile and rapid route for the synthesis of $\mathrm{Cu} / \mathrm{Cu}_{2} \mathrm{O}$ nanoparticles and their application in the Sonogashira coupling reaction of acyl chlorides with terminal alkynes. Catal Sci Technol 4(12):4274-4280. https://doi.org/10.1039/ C4CY00868E

17. Biffis A, Centomo P, Del Zotto A, Zecca M (2018) Pd metal catalysts for cross-couplings and related reactions in the 21st century: a critical review. Chem Rev 118(4):2249-2295. https:// doi.org/10.1021/acs.chemrev.7b00443

18. Biggs-Houck JE, Younai A, Shaw JT (2010) Recent advances in multicomponent reactions for diversity-oriented synthesis. Curr Opin Chem Biol 14(3):371-382. https://doi.org/10.1016/j. cbpa.2010.03.003

19. Boettger R (1859) Ueber die Einwirkung des Leuchtgases auf verschiedene Salzsolutionen, insbesondere auf eine ammoniakalische Kupferchlorürlösung. Justus Liebigs Ann Chem 109(3):351-362. https://doi.org/10.1002/jlac.18591090318

20. Bulut S, Fei Z, Siankevich S, Zhang J, Yan N, Dyson PJ (2015) Aqueous-phase hydrogenation of alkenes and arenes: the growing role of nanoscale catalysts. Catal Today 247:96-103. https://doi.org/10.1016/j.cattod.2014.09.002

21. Cahiez G, Moyeux A (2010) Cobalt-catalyzed cross-coupling reactions. Chem Rev 110(3):1435-1462. https://doi.org/10.1021/cr9000786

22. Chahdoura F, Favier I, Gómez M (2014) Glycerol as suitable solvent for the synthesis of metallic species and catalysis. Chem Eur J 20(35):10884-10893. https://doi.org/10.1002/ chem.201403534

23. Chahdoura F, Pradel C, Gómez M (2014) Copper(I) oxide nanoparticles in glycerol: a convenient catalyst for cross-coupling and azide-alkyne cycloaddition processes. ChemCatChem 6(10):2929-2936. https://doi.org/10.1002/cctc.201402214

24. Chakraborty S, Shah NH, Fishbein JC, Hosmane RS (2011) A novel transition state analog inhibitor of guanase based on azepinomycin ring structure: synthesis and biochemical assessment of enzyme inhibition. Bioorg Med Chem Lett 21(2):756-759. https://doi.org/10.1016/ j.bmcl.2010.11.109

25. Chattopadhyay K, Dey R, Ranu BC (2009) Shape-dependent catalytic activity of copper oxide-supported $\operatorname{Pd}(0)$ nanoparticles for Suzuki and cyanation reactions. Tetrahedron Lett 50(26):3164-3167. https://doi.org/10.1016/j.tetlet.2009.01.027

26. Chirik P, Morris R (2015) Getting down to earth: the renaissance of catalysis with abundant metals. Acc Chem Res 48(9):2495. https://doi.org/10.1021/acs.accounts.5b00385

27. Cordente N, Respaud M, Senocq F, Casanove M-J, Amiens C, Chaudret B (2001) Synthesis and magnetic properties of nickel nanorods. Nano Lett 1(10):565-568. https://doi.org/10. $1021 / \mathrm{n} 10100522$

28. Corriu RJP, Masse JP (1972) Activation of grignard reagents by transition-metal complexes. A new and simple synthesis of trans-stilbenes and polyphenyls. J Chem Soc Chem Commun 3:144a. https://doi.org/10.1039/C3972000144A 
29. Dabiri M, Vajargahy MP (2017) PdCo bimetallic nanoparticles supported on threedimensional graphene as a highly active catalyst for sonogashira cross-coupling reaction. Appl Organomet Chem 31(4):e3594. https://doi.org/10.1002/aoc.3594

30. Dahl JA, Maddux BLS, Hutchison JE (2007) Toward greener nanosynthesis. Chem Rev 107(6):2228-2269. https://doi.org/10.1021/cr050943k

31. Dang-Bao T, Pradel C, Favier I, Gómez M (2017) Making copper(0) nanoparticles in glycerol: a straightforward synthesis for a multipurpose catalyst. Adv Synth Catal 359(16):2832-2846. https://doi.org/10.1002/adsc.201700535

32. Dang-Bao T, Pradel C, Favier I, Gómez M (2019) Bimetallic nanocatalysts in glycerol for applications in controlled synthesis. a structure-reactivity relationship study. ACS Appl. Nano Mater 2(2):1033-1044. https://doi.org/10.1021/acsanm.8b02316

33. Díez-González S (2016) Chapter three-copper(I)-acetylides: access, structure, and relevance in catalysis. In: Pérez PJ (ed) Advances in organometallic chemistry, vol 66. Academic Press, pp 93-141

34. Dong H, Chen YC, Feldmann C (2015) Polyol synthesis of nanoparticles: status and options regarding metals, oxides, chalcogenides, and non-metal elements. Green Chem 17(8):41074132. https://doi.org/10.1039/C5GC00943J

35. Eicher T, Hauptmann S, Speicher A (2013) The chemistry of heterocycles: structures, reactions, synthesis, and applications. Wiley

36. Evano G, Blanchard N, Toumi M (2008) Copper-mediated coupling reactions and their applications in natural products and designed biomolecules synthesis. Chem Rev 108(8):30543131. https://doi.org/10.1021/cr8002505

37. Fakhri A, Naghipour A (2018) Organometallic polymer-functionalized $\mathrm{Fe} 3 \mathrm{O} 4$ nanoparticles as a highly efficient and eco-friendly nanocatalyst for C-C bond formation. Trans Met Chem 43(5):463-472. https://doi.org/10.1007/s11243-018-0233-5

38. Favier I, Pla D, Gómez M (2018) Metal-based nanoparticles dispersed in glycerol: an efficient approach for catalysis. Catal Today 310:98-106. https://doi.org/10.1016/j.cattod.2017.06.026

39. Favier I, Pla D, Gómez M (2019) Palladium nanoparticles in polyols: synthesis, catalytic couplings and hydrogenations. Chem Rev. https://doi.org/10.1021/acs.chemrev.9b00204

40. Favier I, Toro M-L, Lecante P, Pla D, Gómez M (2018) Palladium-mediated radical homocoupling reactions: a surface catalytic insight. Catal Sci Technol 8(18):4766-4773. https:// doi.org/10.1039/C8CY00901E

41. Fiévet F, Ammar-Merah S, Brayner R, Chau F, Giraud M, Mammeri F, Viau G (2018) The polyol process: a unique method for easy access to metal nanoparticles with tailored sizes, shapes and compositions. Chem Soc Rev 47(14):5187-5233. https://doi.org/10.1039/ C7CS00777A

42. Fievet F, Lagier JP, Blin B, Beaudoin B, Figlarz M (1989) Homogeneous and heterogeneous nucleations in the polyol process for the preparation of micron and submicron size metal particles. Solid State Ion 32-33:198-205. https://doi.org/10.1016/0167-2738(89)90222-1

43. Fievet F, Lagier JP, Figlarz M (2013) Preparing monodisperse metal powders in micrometer and submicrometer sizes by the polyol process. MRS Bull 14(12):29-34. https://doi.org/10. $1557 / \mathrm{S} 0883769400060930$

44. Firouzabadi H, Iranpoor N, Gholinejad M, Hoseini J (2011) Magnetite (Fe3O4) nanoparticlescatalyzed sonogashira-hagihara reactions in ethylene glycol under ligand-free conditions. Adv Synth Catal 353(1):125-132. https://doi.org/10.1002/adsc.201000390

45. Firouzabadi H, Iranpoor N, Gholinejad M, Hoseini J (2011b) Magnetite (Fe3O4) nanoparticles-catalyzed Sonogashira-Hagihara reactions in ethylene glycol under ligand-free conditions. [Erratum to document cited in CA154:310261]. Adv Synth Catal 353(7):1027. https://doi.org/10.1002/adsc.201190017

46. Formenti D, Ferretti F, Scharnagl FK, Beller M (2019) Reduction of nitro compounds using 3d-non-noble metal catalysts. Chem Rev 119(4):2611-2680. https://doi.org/10.1021/ acs.chemrev.8b00547

47. Frindy S, El Kadib A, Lahcini M, Primo A, Garcia H (2015) Copper nanoparticles stabilized in a porous chitosan aerogel as a heterogeneous catalyst for C-S cross-coupling. ChemCatChem 7(20):3307-3315. https://doi.org/10.1002/cctc.201500565 
48. Gandeepan P, Müller T, Zell D, Cera G, Warratz S, Ackermann L (2019) 3d transition metals for C-H activation. Chem Rev 119(4):2192-2452. https://doi.org/10.1021/acs.chemrev.8b00507

49. Ganem B (2009) Strategies for innovation in multicomponent reaction design. Acc Chem Res 42(3):463-472. https://doi.org/10.1021/ar800214s

50. Gawande MB, Goswami A, Felpin F-X, Asefa T, Huang X, Silva R, Varma RS (2016) Cu and Cu-based nanoparticles: synthesis and applications in catalysis. Chem Rev 116(6):3722-3811. https://doi.org/10.1021/acs.chemrev.5b00482

51. Ghiasbeigi E, Soleiman-Beigi M (2019) Copper immobilized on isonicotinic acid hydrazide functionalized nano-magnetite as a novel recyclable catalyst for direct synthesis of phenols and anilines. Chem Select 4(12):3611-3619. https://doi.org/10.1002/slct.201803770

52. Gholinejad M, Zareh F, Najera C (2018) Nitro group reduction and Suzuki reaction catalysed by palladium supported on magnetic nanoparticles modified with carbon quantum dots generated from glycerol and urea. Appl Organomet Chem 32(1):e3984. https://doi.org/10.1002/ aoc. 3984

53. Ghorbani-Choghamarani A, Tahmasbi B, Moradi P (2016) Palladium-S-propyl-2aminobenzothioate immobilized on $\mathrm{Fe} 3 \mathrm{O} 4$ magnetic nanoparticles as catalyst for Suzuki and Heck reactions in water or poly(ethylene glycol). Appl Organomet Chem 30(6):422-430. https://doi.org/10.1002/aoc.3449

54. Ghosh Chaudhuri R, Paria S (2012) Core/shell nanoparticles: classes, properties, synthesis mechanisms, characterization, and applications. Chem Rev 112(4):2373-2433. https://doi. org/10.1021/cr100449n

55. Gilman H, Lichtenwalter M (1939) Relative reactivities of organometallic compounds. XXV. Coupling reaction with halides of group VIII metals. J Am Chem Soc 61(4):957-959. https:// doi.org/10.1021/ja01873a056

56. Grasso S, Micale N, Monforte A-M, Monforte P, Polimeni S, Zappalà M (2000) Synthesis and in vitro antitumour activity evaluation of 1 -aryl- $1 H, 3 H$-thiazolo[4,3- $b$ ]quinazolines. Eur J Med Chem 35(12):1115-1119. https://doi.org/10.1016/S0223-5234(00)01195-8

57. Anastas PT, Warner JC (2000) Green chemistry. Org Process Res Dev 4(5):437-438. https:// doi.org/10.1021/op000054t

58. Haji M (2016) Multicomponent reactions: a simple and efficient route to heterocyclic phosphonates. Beilstein J Org Chem 12:1269-1301. https://doi.org/10.3762/bjoc.12.121

59. Hajipour AR, Abolfathi P (2017) Novel triazole-modified chitosan@nickel nanoparticles: efficient and recoverable catalysts for Suzuki reaction. New J Chem 41(6):2386-2391. https:// doi.org/10.1039/C6NJ03789E

60. Hajipour AR, Rezaei F, Khorsandi Z (2017) Pd/Cu-free Heck and Sonogashira cross-coupling reaction by Co nanoparticles immobilized on magnetic chitosan as reusable catalyst. Green Chem 19(5):1353-1361. https://doi.org/10.1039/C6GC03377F

61. Handa S, Slack ED, Lipshutz BH (2015) Nanonickel-catalyzed Suzuki-Miyaura crosscouplings in water. Angew Chem Int 54(41):11994-11998. https://doi.org/10.1002/anie. 201505136

62. Heiz U, Landman U (2007) Nanocatalysis. Springer, Berlin

63. Heravi MM, Zadsirjan V, Hajiabbasi P, Hamidi H (2019) Advances in Kumada-Tamao-Corriu cross-coupling reaction: an update. Monatsh Chem 150(4):535-591. https://doi.org/10.1007/ s00706-019-2364-6

64. Irrgang T, Kempe R (2019) 3d-metal catalyzed N- and C-alkylation reactions via borrowing hydrogen or hydrogen autotransfer. Chem Rev 119(4):2524-2549. https://doi.org/10.1021/ acs.chemrev.8b00306

65. Joule JA, Mills K (2010) Heterocyclic chemistry. Wiley

66. Kataria M, Pramanik S, Kaur N, Kumar M, Bhalla V (2016) Ferromagnetic $\alpha$-Fe2O3 NPs: a potential catalyst in Sonogashira-Hagihara cross coupling and hetero-Diels-Alder reactions. Green Chem 18(6):1495-1505. https://doi.org/10.1039/C5GC02337H

67. Kaushik M, Moores A (2017) New trends in sustainable nanocatalysis: emerging use of earth abundant metals. Curr Opin Green Sustain Chem 7:39-45. https://doi.org/10.1016/j.cogsc. 2017.07.002 
68. Kerton F, Marriott R (2013) Alternative solvents for green chemistry. Roy Soc Chem 2

69. Kharasch MS, Fields EK (1941) Factors determining the course and mechanisms of grignard reactions. IV. The effect of metallic halides on the reaction of aryl grignard reagents and organic halides 1. J Am Chem Soc 63(9):2316-2320. https://doi.org/10.1021/ja01854a006

70. Khurana JM, Vij K (2010) Nickel nanoparticles catalyzed Knoevenagel condensation of aromatic aldehydes with barbituric acids and 2-thiobarbituric acids. Catal Lett 138(1):104-110. https://doi.org/10.1007/s10562-010-0376-2

71. Khurana JM, Vij K (2011) Nickel nanoparticles catalyzed chemoselective Knoevenagel condensation of Meldrum's acid and tandem enol lactonizations via cascade cyclization sequence. Tetrahedron Lett 52(28):3666-3669. https://doi.org/10.1016/j.tetlet.2011.05.032

72. Khurana JM, Yadav S (2012) Highly monodispersed PEG-stabilized Ni nanoparticles: proficient catalyst for the synthesis of biologically important spiropyrans. Aust J Chem 65(3):314-319. https://doi.org/10.1071/CH11444

73. Kidwai M, Mishra NK, Bhardwaj S, Jahan A, Kumar A, Mozumdar S (2010) Cu nanoparticles in PEG: a new recyclable catalytic system for $\mathrm{N}$-arylation of amines with aryl halides. ChemCatChem 2(10):1312-1317. https://doi.org/10.1002/cctc.201000062

74. Klajn R (2014) Spiropyran-based dynamic materials. Chem Soc Rev 43(1):148-184. https:// doi.org/10.1039/C3CS60181A

75. Kotovshchikov YN, Latyshev GV, Lukashev NV, Beletskaya IP (2015) Alkynylation of steroids via Pd-free Sonogashira coupling. Org Biomol Chem 13(19):5542-5555. https:// doi.org/10.1039/C5OB00559K

76. Kunz K, Scholz U, Ganzer D (2003) Renaissance of Ullmann and Goldberg reactionsprogress in copper catalyzed C-N-C-O- and C-S-coupling. Synlett 2003(15):2428-2439. https://doi.org/10.1055/s-2003-42473

77. LaGrow AP, Ingham B, Cheong S, Williams GVM, Dotzler C, Toney MF, Tilley RD (2012) Synthesis, alignment, and magnetic properties of monodisperse nickel nanocubes. J Am Chem Soc 134(2):855-858. https://doi.org/10.1021/ja210209r

78. Langeslay RR, Kaphan DM, Marshall CL, Stair PC, Sattelberger AP, Delferro M (2019) Catalytic applications of vanadium: a mechanistic perspective. Chem Rev 119(4):2128-2191. https://doi.org/10.1021/acs.chemrev.8b00245

79. Liori AA, Stamatopoulos IK, Papastavrou AT, Pinaka A, Vougioukalakis GC (2018) A sustainable, user-friendly protocol for the Pd-free sonogashira coupling reaction. Eur J Org Chem 2018(44):6134-6139. https://doi.org/10.1002/ejoc.201800827

80. Liu Q, Xu M, Zhao J, Yang Z, Qi C, Zeng M, Wang B (2018) Microstructure and catalytic performances of chitosan intercalated montmorillonite supported palladium (0) and copper (II) catalysts for Sonogashira reactions. Int J Biol Macromol 113:1308-1315. https://doi.org/ 10.1016/j.ijbiomac.2018.03.066

81. Liu X, Zhao X, Lu M (2015) A highly water-dispersible and magnetically separable palladium catalyst based on functionalized poly(ethylene glycol)-supported iminophosphine for SuzukiMiyaura coupling in water. Appl Organomet Chem 29(6):419-424. https://doi.org/10.1002/ aoc. 3308

82. Lukyanov BS, Lukyanova MB (2005) Spiropyrans: synthesis, properties, and application (review). Chem Heterocycl Compd 41(3):281-311. https://doi.org/10.1007/s10593-0050148-x

83. Maleki A, Aghaei M, Ghamari N (2015) Synthesis of benzimidazolo[2,3-b]quinazolinone derivatives via a one-pot multicomponent reaction promoted by a chitosan-based composite magnetic nanocatalyst. Chem Lett 44(3):259-261. https://doi.org/10.1246/cl.141074

84. Maleki A, Jafari AA, Yousefi S, Eskandarpour V (2015) An efficient protocol for the one-pot multicomponent synthesis of polysubstituted pyridines by using a biopolymer-based magnetic nanocomposite. C R Chim 18(12):1307-1312. https://doi.org/10.1016/j.crci.2015.09.002

85. Maleki A, Kamalzare M (2014) An efficient synthesis of benzodiazepine derivatives via a onepot, three-component reaction accelerated by a chitosan-supported superparamagnetic iron oxide nanocomposite. Tetrahedron Lett 55(50):6931-6934. https://doi.org/10.1016/j.tetlet. 2014.10.120 
86. Maleki A, Niksefat M, Rahimi J, Taheri-Ledari R (2019) Multicomponent synthesis of pyrano[2,3-d]pyrimidine derivatives via a direct one-pot strategy executed by novel designed cooperated Fe3O4@polyvinyl alcohol magnetic nanoparticles. Mater Today Chem 13:110-120. https://doi.org/10.1016/j.mtchem.2019.05.001

87. Maleki A, Zand P, Mohseni Z, Firouzi-Haji R (2018) Green composite nanostructure (Fe3O4@PEG-SO3H): Preparation, characterization and catalytic performance in the efficient synthesis of $\beta$-amino carbonyl compounds at room temperature. Nano-Struct Nano-Objects 16:31-37. https://doi.org/10.1016/j.nanoso.2018.03.012

88. Martínez-Prieto LM, Chaudret B (2018) Organometallic ruthenium nanoparticles: synthesis, surface chemistry, and insights into ligand coordination. Acc Chem Res 51(2):376-384. https://doi.org/10.1021/acs.accounts.7b00378

89. Metal Nanoclusters in Catalysis and Materials Science: The Issue of Size Control (2011). Elsevier Science, Amsterdam

90. Mitrofanov AY, Murashkina AV, Martín-García I, Alonso F, Beletskaya IP (2017) Formation of C-C, C-S and C-N bonds catalysed by supported copper nanoparticles. Catal Sci Technol 7(19):4401-4412. https://doi.org/10.1039/C7CY01343D

91. Moglie Y, Mascaró E, Nador F, Vitale C, Radivoy G (2008) Nanosized iron- or coppercatalyzed homocoupling of aryl, heteroaryl, benzyl, and alkenyl grignard reagents. Synth Commun 38(22):3861-3874. https://doi.org/10.1080/00397910802238726

92. Mohammadi R, Kassaee MZ (2013) Sulfochitosan encapsulated nano-Fe3O4 as an efficient and reusable magnetic catalyst for green synthesis of 2-amino-4H-chromen-4-yl phosphonates. J Mol Catal A: Chem 380:152-158. https://doi.org/10.1016/j.molcata.2013. 09.027

93. Mondal P, Bhanja P, Khatun R, Bhaumik A, Das D, Manirul Islam S (2017) Palladium nanoparticles embedded on mesoporous $\mathrm{TiO} 2$ material (Pd@MTiO2) as an efficient heterogeneous catalyst for Suzuki-Coupling reactions in water medium. J Colloid Interface Sci 508:378-386. https://doi.org/10.1016/j.jcis.2017.08.046

94. Mondal S (2016) Recent advancement of Ullmann-type coupling reactions in the formation of C-C bond. ChemTexts 2(4):17. https://doi.org/10.1007/s40828-016-0036-2

95. Nakamura E, Hatakeyama T, Ito S, Ishizuka K, Ilies L, Nakamura M (2013) Iron-catalyzed cross-coupling reactions. Org React $1-210$

96. Nasrollahzadeh M, Sajjadi M, Ghorbannezhad F, Sajadi SM (2018) A review on recent advances in the application of nanocatalysts in A3 coupling reactions. Chem Rec 18(10):1409_ 1473. https://doi.org/10.1002/tcr.201700100

97. Neiva EGC, Bergamini MF, Oliveira MM, Marcolino LH, Zarbin AJG (2014) PVP-capped nickel nanoparticles: synthesis, characterization and utilization as a glycerol electrosensor. Sens Actuator B Chem 196:574-581. https://doi.org/10.1016/j.snb.2014.02.041

98. Park J, Kang E, Son SU, Park HM, Lee MK, Kim J, Hyeon T (2005) Monodisperse nanoparticles of $\mathrm{Ni}$ and NiO: synthesis, characterization, self-assembled superlattices, and catalytic applications in the Suzuki coupling reaction. Adv Mater 17(4):429-434. https://doi.org/10. 1002/adma.200400611

99. Patete JM, Peng X, Koenigsmann C, Xu Y, Karn B, Wong SS (2011) Viable methodologies for the synthesis of high-quality nanostructures. Green Chem 13(3):482-519. https://doi.org/ 10.1039/C0GC00516A

100. Peng J-B, Wu F-P, Wu X-F (2019) First-row transition-metal-catalyzed carbonylative transformations of carbon electrophiles. Chem Rev 119(4):2090-2127. https://doi.org/10.1021/ acs.chemrev. 8 b00068

101. Pozharskii AF, Soldatenkov AT, Katritzky AR (2011) Heterocycles in industry and technology. In: Pozharskii AF, Soldatenkov AT, Katritzky AR (eds) Heterocycles in life and society, pp 209-246

102. Prabhu RN, Lakshmipraba J (2017) A nickel(II) thiosemicarbazonato complex: synthesis, structure, electrochemistry, and application in catalytic coupling of terminal alkynes with arylboronic acids. Transit Metal Chem 42(7):579-585. https://doi.org/10.1007/s11243-017$0162-8$ 
103. Prabhu RN, Ramesh R (2016) Square-planar Ni(II) thiosemicarbazonato complex as an easily accessible and convenient catalyst for Sonogashira cross-coupling reaction. Tetrahedron Lett 57(44):4893-4897. https://doi.org/10.1016/j.tetlet.2016.09.049

104. Prechtl MHG (2017) Nanocatalysis in ionic liquids. Wiley-VCH, Weinheim

105. Reina A, Favier I, Pradel C, Gómez M (2018) Stable Zero-Valent nickel nanoparticles in glycerol: synthesis and applications in selective hydrogenations. Adv Synth Catal 360(18):3544-3552. https://doi.org/10.1002/adsc.201800786

106. Roucoux A, Schulz J, Patin H (2002) Reduced transition metal colloids: a novel family of reusable catalysts? Chem Rev 102(10):3757-3778. https://doi.org/10.1021/cr010350j

107. Safari J, Javadian L (2015) Ultrasound assisted green synthesis of 2-amino-4H-chromene derivatives catalyzed by $\mathrm{Fe} 3 \mathrm{O} 4$-functionalized nanoparticles with chitosan as a novel and reusable magnetic catalyst. Ultrason Sonochem 22:341-348. https://doi.org/10.1016/j. ultsonch.2014.02.002

108. Sambiagio C, Marsden SP, Blacker AJ, McGowan PC (2014) Copper catalysed Ullmann type chemistry: from mechanistic aspects to modern development. Chem Soc Rev 43(10):35253550. https://doi.org/10.1039/C3CS60289C

109. San K, Shon Y-S (2018) Synthesis of Alkanethiolate-capped Metal nanoparticles using alkyl thiosulfate ligand precursors: a method to generate promising reagents for selective catalysis. Nanomaterials 8(5):346. https://doi.org/10.3390/nano8050346

110. Schmid G (2011) Nanoparticles: from theory to application. Wiley

111. Serp, P., Philippot, K., Somorjai, G. A., \& Chaudret, B. (2012). Nanomaterials in Catalysis: Wiley

112. Shaabani A, Afshari R (2018) Magnetic Ugi-functionalized graphene oxide complexed with copper nanoparticles: Efficient catalyst toward Ullman coupling reaction in deep eutectic solvents. J Colloid Interface Sci 510:384-394. https://doi.org/10.1016/j.jcis.2017.09.089

113. Shah AP, Sharma AS, Jain S, Shimpi NG (2018) Microwave assisted one pot three component synthesis of propargylamines, tetra substituted propargylamines and pyrrolo[1,2-a]quinolines using CuNPs@ZnO-PTh as a heterogeneous catalyst. New J Chem 42(11):8724-8737.https:// doi.org/10.1039/C8NJ00410B

114. Sharghi H, Aberi M (2014) Ligand-free copper(I) oxide nanoparticle catalyzed threecomponent synthesis of $2 \mathrm{H}$-indazole derivatives from 2-halobenzaldehydes, amines and sodium azide in polyethylene glycol as a green solvent. Synlett 25(8):1111-1115. https:// doi.org/10.1055/s-0033-1340979

115. Song J-Y, Zhou X, Song H, Liu Y, Zhao H-Y, Sun Z-Z, Chu W-Y (2018) Visible-light-assisted cobalt-2-(hydroxyimino)-1-phenylpropan-1-one complex catalyzed Pd/Cu-free SonogashiraHagihara cross-coupling reaction. ChemCatChem 10(4):758-762. https://doi.org/10.1002/ cctc. 201701253

116. Sonogashira K (2002) Development of Pd-Cu catalyzed cross-coupling of terminal acetylenes with sp2-carbon halides. J Organomet Chem 653(1):46-49. https://doi.org/10.1016/S0022328X(02)01158-0

117. Swamy KCK, Kumar NNB, Balaraman E, Kumar KVPP (2009) Mitsunobu and related reactions: advances and applications. Chem Rev 109(6):2551-2651. https://doi.org/10.1021/ cr800278z

118. Tamao K, Sumitani K, Kumada M (1972) Selective carbon-carbon bond formation by crosscoupling of Grignard reagents with organic halides. Catalysis by nickel-phosphine complexes. J Am Chem Soc 94(12):4374-4376. https://doi.org/10.1021/ja00767a075

119. Thomas AA, Denmark SE (2016) Pre-transmetalation intermediates in the Suzuki-Miyaura reaction revealed: the missing link. Science 352(6283):329-332. https://doi.org/10.1126/ science.aad6981

120. Thomas AM, Sujatha A, Anilkumar G (2014) Recent advances and perspectives in coppercatalyzed Sonogashira coupling reactions. RSC Adv 4(42):21688-21698. https://doi.org/10. 1039/C4RA02529F

121. Thota S, Crans DC, Mei W, Wu Q (2018) Applications of metal nanoparticles in medicine/metal nanoparticles as anticancer agents. In: Metal nanoparticles. Wiley-VCH Verlag GmbH \& Co. KGaA, pp 169-190 
122. Torimoto T, Kameyana T, Kuwabata S (2017) Top-down synthesis methods for nanoscale catalysts. In: Prechtl MHG (ed) Nanocatalysis in ionic liquids. Wiley-VCH, Weinheim, pp 171-205

123. Trammell R, Rajabimoghadam K, Garcia-Bosch I (2019) Copper-promoted functionalization of organic molecules: from biologically relevant $\mathrm{Cu} / \mathrm{O} 2$ model systems to organometallic transformations. Chem Rev 119(4):2954-3031. https://doi.org/10.1021/acs.chemrev.8b00368

124. Tsuji J (2004) Palladium reagents and catalysts: new perspectives for the 21 st century. Wiley, West Sussex

125. Ullmann F, Bielecki J (1901) Ueber synthesen in der biphenylreihe. Ber Dtsch Chem Ges 34(2):2174-2185. https://doi.org/10.1002/cber.190103402141

126. Veisi H, Najafi S, Hemmati S (2018) Pd(II)/Pd(0) anchored to magnetic nanoparticles (Fe3O4) modified with biguanidine-chitosan polymer as a novel nanocatalyst for Suzuki-Miyaura coupling reactions. Int J Biol Macromol 113:186-194. https://doi.org/10.1016/j.ijbiomac. 2018.02.120

127. Wang D, Astruc D (2017) The recent development of efficient Earth-abundant transition-metal nanocatalysts. Chem Soc Rev 46(3):816-854. https://doi.org/10.1039/C6CS00629A

128. Warner JC, Cannon AS, Dye KM (2004) Green chemistry. Environ Impact Assess Rev 24(7):775-799. https://doi.org/10.1016/j.eiar.2004.06.006

129. Wei D, Darcel C (2019) Iron catalysis in reduction and hydrometalation reactions. Chem Rev 119(4):2550-2610. https://doi.org/10.1021/acs.chemrev.8b00372

130. Wender PA (2014) Toward the ideal synthesis and molecular function through synthesisinformed design. Nat Prod Rep 31(4):433-440. https://doi.org/10.1039/C4NP00013G

131. Xia H, Xie K, Zou G (2017) Advances in spiropyrans/spirooxazines and applications based on fluorescence resonance energy transfer (FRET) with fluorescent materials. Molecules 22(12):2236

132. Yavuz K, Kuecuekbay H (2018) Efficient and green catalytic system incorporating new benzimidazolium salts for the Sonogashira cross-coupling reaction. Appl Organomet Chem 32(1):n/a. https://doi.org/10.1002/aoc.3897

133. Yonezawa T (2018) Application 78 - preparation of metal nanoparticles and their application for materials. In: Naito M, Yokoyama T, Hosokawa K, Nogi K (eds) Nanoparticle technology handbook, 3rd edn. Elsevier, pp 829-837

134. Zhang Y, Erkey C (2006) Preparation of supported metallic nanoparticles using supercritical fluids: a review. J Supercrit Fluids 38(2):252-267. https://doi.org/10.1016/j.supflu.2006. 03.021

135. Zhong Y, Gong X, Zhu X, Ni Z, Wang H, Fu J, Han W (2014) In situ generated nickel nanoparticle-catalyzed carbonylative Suzuki reactions of aryl iodides with arylboronic acids at ambient CO pressure in poly(ethylene glycol). RSC Adv 4(108):63216-63220. https://doi. org/10.1039/C4RA10739J

136. Zhou B, Hermans S, Somorjai GA (2004) Nanotechnology in catalysis. Kluwer/Plenum, New York

137. Zhou L, Gao C, Xu W (2010) Robust Fe3O4/SiO2-Pt/Au/Pd magnetic nanocatalysts with multifunctional hyperbranched polyglycerol amplifiers. Langmuir 26(13):11217-11225. https:// doi.org/10.1021/la100556p

138. Zhu J, Bienaymé H (2006) Multicomponent reactions. Wiley 